\title{
Diabetes drugs and the incidence of solid cancers: a survey of the current evidence
}

\section{Marco Tuccori, Irma Convertino, Maria Teresa Galiulo, Alessandra Marino, Alice Capogrosso-Sansone \& Corrado Blandizzi}

To cite this article: Marco Tuccori, Irma Convertino, Maria Teresa Galiulo, Alessandra Marino, Alice Capogrosso-Sansone \& Corrado Blandizzi (2017): Diabetes drugs and the incidence of solid cancers: a survey of the current evidence, Expert Opinion on Drug Safety, DOI: 10.1080/14740338.2017.1361401

To link to this article: http://dx.doi.org/10.1080/14740338.2017.1361401

Accepted author version posted online: 27 Jul 2017.

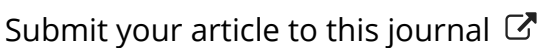

View related articles

View Crossmark data $\nearrow$ 
Publisher: Taylor \& Francis

Journal: Expert Opinion on Drug Safety

DOI: $10.1080 / 14740338.2017 .1361401$

Diabetes drugs and the incidence of solid cancers: a survey of the current evidence

Marco Tuccori, ${ }^{1}$ Irma Convertino, ${ }^{2}$ Maria Teresa Galiulo, ${ }^{2}$ Alessandra Marino, ${ }^{2}$ Alice CapogrossoSansone, ${ }^{2}$ Corrado Blandizzi, ${ }^{1,2}$

${ }^{1}$ Unit of Adverse Drug Reaction Monitoring, University Hospital of Pisa, Pisa, Italy;

${ }^{2}$ Department of Clinical and Experimental Medicine, University of Pisa, Pisa, Italy;

\section{*Corresponding author}

Tel: +39-050-2218761; Fax: +39-050-992071; E-mail: m.tuccori@ao-pisa.toscana.it 


\section{Abstract}

Introduction: The evaluation of the relationship between the use of antidiabetic drug and the occurrence of cancer is extremely challenging, both from the clinical and pharmacoepidemiological standpoint. This narrative review described the current evidence supporting a relationship between the use of antidiabetic drugs and the incidence of solid cancers.

Areas Covered: Data from pharmacoepidemiological studies on cancer incidence were presented for the main antidiabetic drugs and drug classes, including human insulin and insulin analogues, metformin, sulfonylureas, glinides, alpha-glucosidase inhibitors, thiazolidinediones, incretin mimetics, and sodium glucose co-transporter 2 inhibitors. The relationship between the use of antidiabetics and the incidence of solid cancer was described in strata by any cancer and by organspecific cancer and by drug and by drug classes. Information supporting biological evidence and putative mechanisms were also provided.

Expert Opinion: The history of exploration of the relationship between antidiabetic drugs and the risk of solid cancers has showed several issues. Unrecognized biases and misinterpretations of study results have had important consequences that delayed the identification of actual risk and benefits of the use of antidiabetic drugs associated with cancer occurrence or progression. The lesson learned from the past should address the future research in this area, since in the majority of cases findings are controversial and confirmatory studies are warranted. 
Keywords: diabetes, antidiabetic drugs, solid cancer, pharmacoepidemiological studies, chemoprevention

\section{Article highlights}

- The relationship between the exposure to antidiabetic drugs and the incidence of solid cancer was explored in many observational studies. Unfortunately, these studies are easily subjected to bias and often provided misleading results.

- In the majority of cases, the current evidence is controversial and good quality observational studies are required. With very few exceptions, a cancerogenic effect of antidiabetic drugs seems unlikely as well as a chemopreventive activity, and the benefit-risk profile of these drugs remained favorable.

- Caution should be recommended in the conduction of future studies, particularly when designing the study, interpreting their results, and taking consequent regulatory decision. 


\section{Introduction}

Exploring the relationship between the use of a drug and the occurrence of any cancer is extremely challenging, both from the clinical and pharmacoepidemiological standpoint. This is particularly true for antidiabetic medications, for several reasons. First, there is a biological and epidemiological intimate link between type 2 diabetes (T2DM) and related-factors (e.g. obesity, hyperinsulinemia, hyperglycemia, hyperlipidemia, increased oxidative stress and inflammation) and the initiation, promotion, and progression of several kinds of malignancies. T2DM per se is independently associated with the risk of cancer and cancer-related mortality. Therefore, weighting the contribution of disease-related factors to cancer occurrence during an antidiabetic treatment can be complicated. ${ }^{12}$ Second, antidiabetic medications are prescribed sequentially and often in response to T2DM progression. As a consequence, a potential causal role of previous and combined antidiabetic medications should be always taken into account, particularly for long term outcomes, such as cancer. Furthermore, since T2DM severity has been suggested as a potential risk factor for the onset of several neoplasms, ${ }^{3}$ comparisons among patients exposed to different lines of antidiabetic medications could be misleading, and the choice of the comparator group as well as the definition of exposure may heavily affect the results of the analysis. ${ }^{4}$ Finally, even assuming that investigating putative associations of antidiabetic drugs with cancer using healthcare administrative databases could be easy, it is important to remark that these observational studies are subject to important methodological pitfalls, including prevalent-users bias, detection bias and reverse causality, immortal time bias, time-lag bias, confounding by indication, and residual confoundings. ${ }^{2}$

The immediate consequence of the above-mentioned issues is that studies investigating associations of antidiabetic drugs with several kinds of cancer have provided conflicting results. In this review, to cope with the very large amount of published data in the field, we have 
summarized the results of studies that evaluated associations of each category of antidiabetic drugs with any cancer and site-specific cancers. When the evidence was robust, studies investigating the association of a specific drug and a specific kind of malignancy have been also introduced and commented in detail. Finally, a summary of the available biological evidence supporting a cancer-inducing or a cancer-protecting effect was also provided (see box-1). Particular attention was paid to the methodological flaws that were likely to affect the study findings.

\section{Insulin and Insulin analogues}

\subsection{Rsk for any cancer}

The hypothesis that insulin and insulin analogues may trigger or promote cancer in several organs and tissues stands on a reliable biological rationale (Box 1). A relationship between the use of insulin and insulin analogues (the most investigated in human has been insulin-glargine vs other insulin types) and all cancers was highlighted in the earliest observational studies. ${ }^{5-11}$ However, important methodological shortcomings made the results of these studies questionable, and subsequent investigations were not able to replicate the initial findings. ${ }^{21011}$

The majority of most recent observational studies $^{12}$ and meta-analyses ${ }^{13-15}$ suggest a neutral effect of insulin glargine and other insulins for all cancer types. In the recently published Outcome Reduction with an Initial Glargine Intervention (ORIGIN) trial, ${ }^{16}$ a large ( $n=12537$ patients) randomized clinical trial (RCT) designed to assess cardiovascular endpoints, cancers were included as a secondary endpoints. This study compared insulin glargine with a standard care based on investigator's best judgment and local guidelines. Results of this RCT did not confirm any risk of cancer in patients receiving insulin glargine. ${ }^{16}$ Unfortunately, even this study has important methodological limitations (e.g. not designed specifically to investigate cancer, short follow-up 
period, uncertainties in the assessment of concurrent medications and cancer diagnosis), and therefore its results cannot be taken as a conclusive evidence.

\subsection{The risk for site-specific cancers}

Site-specific cancers were investigated in some studies. An analysis performed on a cohort of 114,841 patients reported a statistically significant risk of breast cancer for treatment with insulin glargine as compared with other insulins. ${ }^{8}$ However, a subsequent study on the same population with a longer follow up did not confirm the initially detected risk. ${ }^{17}$ Another study suggested a protective effect of insulin glargine vs any cancer compared with human insulin (hazard ratio, HR 0.75, 95\% confidence interval $[\mathrm{Cl}]$ 0.71-0.80), while in contrast the authors found statistically significant risk for breast cancer ( $\mathrm{HR} 1.58, \mathrm{Cl} 1.22-2.05) .{ }^{18}$ Breast cancer was not associated with the use of any insulin (glargine, lispro, aspart, and human) in other observational studies. ${ }^{19-21}$ Likewise, the risk of breast cancer was not confirmed in a more recent meta-analysis of 13 observational studies (HR 1.04, Cl 0.91-1.17). ${ }^{22}$ A meta-analysis of 19 observational studies suggested that the new use of any insulin carries a significant risk of developing pancreatic cancer (relative risk, RR 3.18, $\mathrm{Cl} 3.27-3.71$ ), while the new use of insulin glargine seems to be associated with a statistically significant risk of pancreatic (RR 1.63, Cl 1.05-2.51) and prostate cancer (RR 2.68, Cl 1.50-4.79), while exerting a protective effect on colon cancer ( $\mathrm{RR} 0.78, \mathrm{Cl} 0.64-0.94){ }^{23}$ Notably, the authors of both meta-analyses recommended caution in the interpretation of their own results, due to important limitations of the included studies.

\subsection{Conclusion}


Overall, based on the current evidence, the association of insulin-based treatments with the risk of any cancer appears to be unlikely, although further studies with adequate follow-up periods would be welcome. ${ }^{24}$

\section{Metformin}

\subsection{Risk for any cancer}

In 2005 , an observational study ${ }^{25}$ showed a impressive protective effect of metformin against any cancer, thus triggering a "domino" effect that initially led to other observational studies and later to clinical trials to test the hypothesis that metformin could be used as an anticancer drug. In parallel, these observations fostered biological investigations to understand the mechanism underlying the effect of metformin on cell growth and proliferation. The possibility of re-inventing metformin, a cheap drug with a well-known safety profile, as an effective treatment for cancer chemoprevention suddenly appeared as extremely appealing. Moreover, evidence was provided that the biological plausibility of the reduction in the risk of cancer associated with metformin is supported by several mechanisms (Box 1$)^{26}$

\subsection{Risk for site-specific cancers}

Retrospective observational studies provided conflictual evidence about the chemopreventive effect of metformin against several kinds of cancer. Indeed, some studies showed remarkable protective effects ${ }^{27-30}$ while many others and often more recently published studies failed in demonstrating a statistically significant benefit. ${ }^{31-42}$ Nevertheless, the initial evidence was considered robust to such an extent to justify large investments in RCTs designed to 
confirm the effectiveness of metformin in reducing cancer risk and mortality. A recent review pointed out that up to 2016 over 5,000 participants were expected to enroll in trials examining the effect of metformin on tumorigenesis in multiple organ systems, ${ }^{43}$ including: 13 studies on breast cancer; 5 on colon cancer; 8 on endometrial hyperplasia or early stage endometrial cancer; 10 on prostate cancer, and 2 on the effect of metformin on progression of hepatitis $C$ cirrhosis to liver cancer. ${ }^{43}$ Chae and co-workers ${ }^{26}$ described 55 ongoing clinical trials in various stages that were evaluating metformin as monotherapy (11 trials) or in combination with cytotoxic chemotherapy (38 trials), or radiotherapy (6 trials). These trials have been designed to evaluate the effect of metformin on biomarkers of cellular proliferation, disease response rate, progression free survival and recurrence free survival. At present, only 3 clinical trials on pancreatic cancer and 1 on breast cancer have been concluded. For pancreatic cancer, the first trial $(n=20)^{44}$ showed that, although the combination of metformin plus paclitaxel was not well tolerated with $42.1 \%$ patients experiencing grade 3-4 toxicity. This trial reported a median overall survival of 133 days and a median progression free survival of 43 days, but it did not meet the endpoint of disease control rate. The second trial $(n=120)^{45}$ showed that although the combination of metformin, gemcitabine and erlotinib was well tolerated, the 6 -month survival rate was $55 \%$ in the metformin arm and $66 \%$ in the placebo arm. Furthermore, no significant difference was observed in the progression free survival and median overall survival when comparing metformin users with non-users. The third study $(n=60)$ was ended for futility after an interim analysis. Indeed, the 6-month progression free survival was $52 \%$ in the control group and $42 \%$ in the metformin group $(p=0.61) .{ }^{46}$ With regard for breast cancer, the only available study $(n=492)$ showed that at 6 months metformin, compared with placebo, may improve some surrogate markers of poor disease outcome (i.e. weight, insulin, glucose, leptin, and C-reactive protein). ${ }^{47}$ 


\subsection{Conclusion}

Current evidence seems to confirm the hypothesis that the benefit reported for metformin by some observational studies in diabetic patients, used as the backbone of the rationale for many clinical trials, was based on time-related biases. ${ }^{48}$ Once these biases are removed, the protective effect of metformin against cancer appear to be of lesser magnitude than previously claimed. Moreover, and most importantly, the putative benefit in non-diabetic individuals remains to be demonstrated. $^{43}$

\section{Sulfonylureas}

\subsection{Risk for any cancer}

Despite their widespread use in clinical practice since long time, there is still uncertainty about the potential effect of sulfonylureas (SUs) on cancer risk in patients with T2DM. This risk is particularly difficult to evaluate due the changes in prescription patterns occurred over years. Indeed, in the nineties, SU were the first line treatment for T2DM, but these were gradually replaced by metformin. Furthermore, their use is still declining, and the number of currently exposed patients is much smaller than in the past. Therefore, in observational studies including data that cover long follow-up periods (e.g. from 1990 to nowadays) differences in the populations of patients taking these drugs (i.e. severity of treated T2DM) should be carefully taken into account. ${ }^{49}$ The majority of studies on SU evaluated the incidence of solid tumors as breast, ${ }^{49-52}$ prostate, ${ }^{495354}$ colorectal, $^{4955}{ }^{2}$ lung, ${ }^{49} 55$ hepatocellular, ${ }^{1}{ }^{1657}$ esophageal, ${ }^{11}$ thyroid, ${ }^{56}$ and pancreatic cancer. ${ }^{58}$ The overall evidence is supportive of protective, neutral or prooncogenic effects. Furthermore, the findings of some of these studies (including non-clinical experiments, Box 1) have suggested that these effects may not be equivalent with all SUs. 
Studies investigating the occurrence of cancer in SUs users provided conflicting results. For instance, while RCTs did not point to a higher cancer risk in SUs treated patients compared with SU non-users, an increased risk was suggested in case-control studies. ${ }^{59} 2$ A systematic review $^{60}$ evaluated 77 studies (33 RCTs, 27 cohort studies, and 17 case-control studies) and found some discrepancies between RCTs and both cohort and case-control studies. Pooling the results of RCTs did not suggest significant effects of SU on the risk of tumors (odds ratio [OR] 0.93, $\mathrm{Cl} 0.77-1.12, \mathrm{n}=33, \mathrm{I}^{2}=30 \%$ ) and malignant tumors ( $\mathrm{OR} 0.96, \mathrm{Cl} 0.78-1.18, \mathrm{n}=32, \mathrm{I}^{2}=26 \%$ ), compared with other hypoglycemic agents. Observational studies (cohort studies and casecontrol studies) suggested a statistically significant increase in the risk of cancer in SUs users versus metformin ( $\mathrm{HR}$ 1.13, $\mathrm{Cl}$ 1.06-1.19), but not versus thiazolidinediones (TZDs) and dipeptidyl-peptidase 4 (DPP-4) inhibitors users (HR 1.09, Cl 0.96-1.24; and HR 1.28, Cl 0.77-2.11, respectively). Interestingly, the trend of cohort studies was toward a non-significant protective effect for SUs users compared with non-SUs users for any cancer (HR 0.67, Cl 0.41-1.11), whereas the trend of case-control studies pointed to a non-significant increase in cancer risk in SUs users vs non-users (OR $1.13, \mathrm{Cl} 0.93-1.37, \mathrm{I}^{2}=76 \%$ ).

A meta-analysis (38 RCTs, 16 cohort studies and 18 case-control studies), ${ }^{61}$ assessing both the risk of cancer and mortality in patients with TDM2 after therapy with different antidiabetic medications, found a statistically significant increased risk for cancer incidence in SU users (RR 1.20, $\mathrm{Cl} 1.13-1.27)$, but not for cancer-related mortality (RR 1.08, $\mathrm{Cl} 0.99-1.18)$. However, this result may be affected by inclusion of observational studies with important methodological issues.

\subsection{Risk for site-specific cancers}


Several studies have evaluated the risk of any cancer or tissue-specific cancer comparing cohort of patients on SUs therapy with those receiving metformin. For instance, a retrospective cohort study ${ }^{55}$ showed a statistically signifcant risk of colorectal (HR 1.94, Cl 1.15-3.27) and lung cancer (HR 1.76, Cl 1.00-3.07) in patient on SUs monotherapy compared with metformin. By contrast, a retrospective observational study ${ }^{59}$ did not found a significant risk of cancer in patients on SUs monotherapy versus those with metformin. It is reasonable to hypothesize that the difference in the risk of cancer in metformin versus SUs users might be attributed to a certain protective anticancer effect of metformin. ${ }^{55}$ It is noteworthy that, unlike metformin, SUs are often used as second-line therapy in patient with longer duration of T2DM. Since cancer occurrence is related to T2DM progression, this would mean a possible selective prescription of SUs to patients with a higher cancer risk compared with those receiving metformin. ${ }^{62}$

\subsection{Cancer risks: any difference across SUs?}

Finally, SUs display different pharmacological properties that might explain within class differences in cancer incidence and mortality. ${ }^{1}$ Indeed, in some observational studies a higher risk of cancer was reported for glibenclamide (also known as glyburide) compared with other SUs. ${ }^{6364}$ A recent population-based cohort study ${ }^{49}$ compared the risk of cancer for glibenclamide versus other second-generation SUs in patients with T2DM. The results pointed toward a nonsignificant increase of any cancer risk with glibenclamide use (HR 1.09, $\mathrm{Cl}$ 0.98-1.22], while a significant increased risk of any cancer was found after longer cumulative durations and doses (> 36 months: HR 1.21, Cl 1.03-1.42; >1,096 DDDs: HR 1.27, Cl 1.06-1.51). If a difference in cancer risk exists, we cannot exclude that this can be explained mainly by a lower protective effect of glibenclamide than by a specific risk associated with glibenclamide use. 


\subsection{Conclusion}

The overall evidence supporting any effect of SUs on cancer incidence and mortality is limited and not conclusive. Further studies are warranted, including investigations aimed at assessing whether the effect on cancer incidence is differential within the class of SUs.

\section{Glinides}

\subsection{Risk for any cancer}

Glinides are expected to exert proliferative effects through their hyper-insulinemic potential, although pre-clinical evidence has shown also protective activities (Box 1). Several observational studies have investigated the risk of any cancer associated with glinides. In many of these studies, glinides were evaluated as a part of large composite groups of antidiabetic treatments, and sometimes these studies lacked an adequate statistical power to evaluate appropriately the sub-groups of patients receiving glinides, particularly when site-specific cancers were examined. ${ }^{15565}$ A nationwide nested case-control study, performed on 108,920 Taiwanese patients with newly diagnosed T2DM, showed a significant increase in the risk of overall cancer for glinides (OR 1.16, Cl 1.06-1.28) with specific risks for liver, colorectal, lung, stomach, and pancreas. ${ }^{66}$ Notably, case and controls were matched for T2DM duration and not for duration of treated T2DM, thus exposing the results to possible time-related bias. However, these results were not confirmed in other observational studies. ${ }^{67}$ For instance, a nested case-control study on 275,164 T2DM patients did not find a significant increase in the risk of cancer for each evaluated antidiabetic drug (OR for repaglinide: $0.96, \mathrm{Cl} 0.66-1.40) .{ }^{67}$ Similarly to the above mentioned study, ${ }^{66}$ inappropriate matching using T2DM duration instead of duration of treated 
T2DM may have biased the results. A retrospective analysis ${ }^{68}$ of the electronic health record-based Cleveland Clinic Diabetes Registry $(n=25,613)$ was cross-indexed with the histology-based tumour registry (48,051 cancer occurrences), over an 8-year period (1998-2006), to analyse the association between cancer incidence and oral T2DM therapy (biguanides, SUs, TZDs and glinides). The comparison of glinides with SUs did not demonstrate an increased cancer risk. ${ }^{68}$ The association of risk for any cancer and glinides has been also recently evaluated in a systematic review and metaanalysis of eight studies ( 3 cohort studies, 3 case-control studies and 2 clinical trials). The results did not show a significant association between glinides and risk of cancer (OR 1.06, CI 0.83-1.37). ${ }^{61}$

\subsection{Risk for site-specific cancers}

Some authors have evaluated the risk of site-specific cancer associated with glinides. Three studies have been specifically designed to assess the risk of endometrial cancer, ${ }^{69}$ urinary bladder cancer $^{70}$ and gastric cancer ${ }^{71}$ in diabetic patients, but none highlighted a significant risk for glinides. In a population-based study in Taiwan, including 36,270 T2DM patients and 145,080 subjects without T2DM from 2005 to 2010, glinides did not show significant effects on the baseline risk of cancers in the digestive system (including liver, pancreas, and colorectal cancer). ${ }^{72}$ However, the results of this study were likely affected by immortal time bias, since the exposure to drugs was calculated from the T2DM diagnosis and not since the first drug prescription. These findings are in line with a previous nationwide, population-based study in Taiwan (2000-2007), exploring the relationship between T2DM and cancer of the digestive tract (esophagus, stomach, small intestine, colon, rectum, liver, gallbladder and pancreas), which showed a lack of association between the use of glinides and digestive cancers. ${ }^{73}$ Another study evaluated the risk of a set of malignancies (liver, colorectal, lung, and urinary bladder cancer) in diabetic patients $(n=606,583)$ who received TZDs, with sub-analysis of other medications. ${ }^{74}$ In this study, glinides were significantly associated with an increased risk for liver (adjusted OR 1.29, Cl 1.15-1.44), colorectal 
(adjusted OR 1.46, Cl 1.30-1.65), bladder (adjusted OR 1.71, $\mathrm{Cl}$ 1.30-2.24) and lung cancer (adjusted OR 1.75, $\mathrm{Cl} 1.38-2.20) .{ }^{74}$ Relevant shortcomings of this study, namely the inclusion of prevalent diabetic patients and the lack of control (or matching) for duration of treated T2DM, may have importantly biased the results. Another study analysed the role of various antidiabetic drugs on hepatocellular carcinoma using the healthcare utilization databases of the Lombardy Region in Italy. ${ }^{75}$ This study included 190 diabetic subjects with a hospital discharge reporting a diagnosis of malignant hepatocellular carcinoma and 3,772 diabetic control subjects. Repaglinide showed a statistically significant increased risk of hepatocellular carcinoma (OR 2.12, Cl 1.38-3.26), with similar findings for insulin and other drugs acting on insulin secretion. Based on this observation, the authors hypothesized that the potential tumorigenic effect of repaglinide on liver, if any, is likely insulin-mediated. ${ }^{75}$

\subsection{Conclusion}

In summary, owing to methodological limitations of the available studies and to the lack of comprehensive evaluations, there is a lack of conclusive evidence supporting an association of glinides with cancer occurrence. ${ }^{12}$

\section{Alpha-glucosidase inhibitors}

\subsection{Risk for any cancer}

The risk of any cancer and tissue specific cancer for alpha-glucosidase inhibitors has been investigated in several studies. The majority of observational studies were performed using the data of the National Health Insurance of Taiwan. ${ }^{55} 71$ 76-81 In many cases, relevant protective 
effects of alpha-glucosidase inhibitors or acarbose, likely due to time-related bias, were found. ${ }^{71-73}$ 7679

A systematic review and meta-analysis of 13 studies $(2$ cohort studies, 6 case-control studies, 5 clinical trials) suggested that alpha-glucosidase inhibitors are associated with a $10 \%$ significant increase in the risk of cancer incidence (RR 1.10, $\mathrm{Cl}$ 1.05-1.15), but not with a signifcant increase in cancer mortality (RR $1.40, \mathrm{Cl} 0.09-21.94) .{ }^{61}$ Other studies did not show a statistically significant association between alpha-glucosidase inhibitors and cancer. A nested case-control study conducted on 275,164 T2DM patients, including 1,040 cases with any cancer and 3,120 controls, did not find a significant increase in the risk of cancer for alpha glucosidase inhibitors (OR $0.76, \mathrm{Cl} 0.48-1.21) .{ }^{67}$ Smaller studies confirmed the lack of a significant effect on the incidence of any cancer. $^{5564}$

6.2 Risk for site-specific cancers

Early pre-clinical evidence of kidney tumour associated with acarbose has not been confirmed in later studies (Box 1). In line with this evidence, a small study of 24 women with T2DM, treated with acarbose in dosages up to $1500 \mathrm{mg}$ daily for 12 months, showed no evidence of kidney tumours. ${ }^{82}$ Conversely, a population-based case-control study using data from the National Health Insurance programme in Taiwan, which included 116 patients with kidney cancer and 464 controls, showed a significant association of alpha-glucosidase inhibitors with the risk of kidney cancer (adjusted OR use vs no use: 4.31, $\mathrm{Cl}$ 1.07-17.3). These results have never been replicated and should be taken with caution given the smaller number of cases analysed. ${ }^{77}$

Evidence of protective effects of alpha glucosidase inhibitors in biomarker studies (Box 1), fostered the conduction of observational studies specifically designed to test whether alpha- 
glucosidase inhibitors or acarbose can be associated with reductions of colorectal cancer incidence in patients with T2DM. In particular, two studies performed in Taiwan confirmed a reduction of $36 \%$ in the risk of colorectal cancer in patients taking alpha-glucosidase inhibitors ${ }^{72}$ and a $27 \%$ protective effect against colorectal cancer for acarbose. ${ }^{76}$ Notably, the results of these studies are likely affected by important time-related bias and must be taken with caution. A third Taiwanese study did not show a significant association of acarbose use with colon cancer (RR 1.255, Cl 0.827$1.906) .^{78}$

Gastric cancer has been also investigated for its putative association with alpha-glucosidase inhibitors. $^{83}$ An observational study showed a $62 \%$ reduction in the risk of gastric cancer associated with alpha-glucosidase inhibitors. ${ }^{71}$ However, this impressive protective effect could be likely explained by an immortal time bias. Similar pictures can be described for protective effects obtained in studies assessing the risk of liver, ${ }^{72}$ breast $^{72}$ and lung cancer ${ }^{79}$ with alpha-glucosidase inhibitors. No risk was observed for bladder ${ }^{80}$ and thyroid cancer. ${ }^{81}$

\subsection{Conclusion}

Based on available data, the association of alpha-glucosidase inhibitors with cancer remains unclear. Further well-designed studies are necessary to clarify a possible effect on cancer incidence and mortality for these drugs.

\section{Thiazolidinediones}

7.1 Risk for any cancer and site-specific cancers 
The thiazolidinediones (TZDs), pioglitazone and rosiglitazone, are likely the most problematic and controversial class of antidiabetic drugs, due to their involvement in drug safety emergencies, including the potential for cancer-inducing effects, over the last decade. ${ }^{84}$

Several studies, including systematic reviews and meta-analyses, have tested the association of TZDs use and any cancer, and the majority of them have suggested a neutral effect. ${ }^{1}$ Among the most recently published, a meta-analysis of 22 clinical trials (13,197 patients receiving TZDs vs 12,359 receiving placebo or active comparators) showed a significant reduction in the incidence of any cancer (OR $0.85, \mathrm{Cl} 0.73-0.98$ ) without any difference between rosiglitazone and pioglitazone. ${ }^{85}$ In particular, subgroup analyses suggested a significant reduction for rosiglitazone (OR 0.82, $\mathrm{Cl}$ 0.69-0.98), but not for pioglitazone (OR 0.66, Cl 0.34-1.28). Another systematic review and meta-analysis of 17 observational studies, testing the association of TZDs use with the risk of overall cancer, found neutral effects ( $\mathrm{RR} 0.96, \mathrm{Cl} 0.91-1.0) .{ }^{86}$ The same study pointed out a significantly lower risk of liver cancer in patients using either rosiglitazone or pioglitazone. ${ }^{86}$ This result was not confirmed in another systematic review and meta-analysis including 334,307 patients with T2DM, where TZDs did not significantly affect the risk of hepatocellular cancer (OR $0.54, \mathrm{Cl}$ 0.28-1.02). ${ }^{87}$ A 6 -year population-based cohort study showed an important dosedependent decrease in cancer risk in diabetic patients using TZDs, for several site-specific cancers, including colorectal cancer, breast, brain, uterus, stomach, prostate, ear-nose-throat, kidney, lung and lymphatic malignancies. ${ }^{88}$ However, the benefit observed in this study likely resulted from methodological shortcomings in the definition of the exposure (immortal time bias) ${ }^{89}$ The risk of colorectal cancer for TZDs did not differ from controls in a systematic review and meta-analysis performed on 840,787 diabetic patients. ${ }^{56}$ Few reports have addressed the risk of breast cancer. In the above mentioned meta-analysis of 22 RCTs, a significant reduction of breast cancer risk for pioglitazone, but not rosiglitazone, was observed. ${ }^{85}$ Further evidence of a neutral effect comes 
from another meta-analysis, including data from 3 case-control and 14 cohort studies, that did not report an association of TZDs with breast cancer. ${ }^{86}$

\subsection{Pioglitazone and bladder cancer}

The only exception to this general quite reassuring scenario is represented by the evidence of a risk of bladder cancer associated with pioglitazone. In 2005, the PROactive randomized controlled trial ${ }^{90}$ unexpectedly showed an increase of cases of bladder cancer with pioglitazone compared with placebo. A similar finding was never observed in clinical trials with rosiglitazone, thus suggesting that this was a pioglitazone specific effect. ${ }^{91} 92$

The above observation fostered a large debate, lasted for years, about the hypothetic biological mechanisms underlying the inducing and/or promoting effect of pioglitazone on bladder cancer (Box 1). In addition, it raised the attention of scientific community and prompted the regulatory agencies to implement appropriate confirmatory studies. ${ }^{93-101}$ In the five year interim analysis of a large observational study, requested by the United States Food and Drug Administration (FDA), using the Kaiser Permanente Northern California database, ${ }^{102}$ the use of pioglitazone for 24 months or more was significantly associated with an increased risk of bladder cancer (HR 1.4, $\mathrm{Cl} 1.03-2.0)$. However, in the final analysis of the same study, which used the same cohort with follow-up extended to 10 years, the use of pioglitazone was no longer significantly associated with an increased risk of bladder cancer in a duration-response fashion. ${ }^{103}$ The retrospective cohort study by Korhonen et al. ${ }^{104}$, prompted by the European Medicine Agency (EMA), showed no evidence of association between ever use of pioglitazone and the risk of bladder cancer compared with never use. These null findings are consistent with those of another large multicohort study. ${ }^{101}$ Amongst the other studies, some supported the findings of the 
PROactive trial, showing a significant increase of the risk ${ }^{93-95}$ while others rejected this association. $^{96-101} 105$ From a methodological standpoint, the conflicting results of the aforementioned studies might reflect the inclusion of prevalent users of pioglitazone in the analyses, ${ }^{95-97100-103}$ the presence of immortal-time bias, ${ }^{95} 96100$ selection bias, ${ }^{97}{ }^{101}$ important residual confounding, ${ }^{93}$ and time-lag bias. ${ }^{97} 102$ In the attempt of overcoming all the relevant shortcomings of the available studies, a cohort study, ${ }^{106}$ involving 145.806 patients with T2DM under treatment with non-insulin antidiabetic drugs, highlighted a signifcant increase in the risk of bladder cancer with pioglitazone rather than other antidiabetic agents (HR 1.63, IC 1.22-2.19), but not for rosiglitazone ( $\mathrm{HR} 1.10, \mathrm{Cl}$ 0.83-1.47). These findings confirmed that the association reported for pioglitazone is likely a drug-specific and not a class effect. Furthermore, this specific cancer risk of pioglitazone varies in a duration-dependent and dose-dependent fashion. ${ }^{106}$

\subsection{Conclusion}

Based on the overall available evidence, both the FDA and the EMA issued restrictions on the use of pioglitazone and required a close monitoring of patients. Nevertheless, the risk-benefit profile of pioglitazone remained favorable as a second or third line treatment for T2DM. ${ }^{107} 108$

\section{Incretin mimetics \\ 8.1 Risk for pancreatic cancer}

The possibility that incretin mimetics, including both glucagon like peptide 1 (GLP-1) receptor agonists and DPP-4 inhibitors, are associated with cancer has been debated after pharmacovigilance studies identified a potential signal of pancreatic cancer. The FDA post- 
marketing surveillance activity recorded some spontaneous reports of pancreatitis and pancreatic cancer associated with incretin mimetics since their marketing authorization. ${ }^{109} 110$ The signal of pancreatic cancer was recently confirmed in a case/non-case study performed on the FDA database particularly for linagliptin, saxagliptin and sitagliptin. ${ }^{111}$ of note, pre-clinical studies have provided controversial results, and different mechanisms can be hypothesized to account for both tumour-protective and tumour-inducing effects (Box 1).

After a review of available evidence, the causal relationship between incretin mimetics and pancreatic cancer was considered unlikely. ${ }^{109} 110$ Indeed, data from observational studies, as discussed below, have provided quite reassuring findings. Most of these studies appear to be reliable, even though in some cases there are relevant limitations possibly related to residual confoundings, ${ }^{67}$ short follow up ${ }^{67112-117}$ or potential protopathic bias. ${ }^{113117118}$

A recent retrospective nested case-control analysis on a cohort of 275,164 T2DM patients in 16 Primary Health Care Centres of Barcelona did not find evidence of risk of any cancer associated with DPP-4 inhibitors (OR 1.01, $\mathrm{Cl}$ 0.59-1.74). ${ }^{67} \mathrm{~A}$ nested case-control analysis, conducted on an international multicentre cohort of 972,384 newly non-insulin antidiabetic users, from 1 January 2007 to 30 June 2013, did not observe a significant risk of pancreatic cancer for incretin therapies compared with SUs (pooled adjusted $\mathrm{HR} 1.02, \mathrm{Cl} 0.84-1.23$ ). ${ }^{118}$ In a retrospective population-based cohort study on Taiwanese patients no differences were reported in the occurrence of pancreatic cancer for incretin users (including saxagliptin, vildagliptin, sitagliptin, exenatide, linagliptin) compared with the matched (1:1) non-incretin group (0.05\% vs $0.08 \%, p=0.3172) .{ }^{112}$ A retrospective population-based cohort study from the United Kingdom Clinical Practice Research Datalink, including 182,428 adult patients, did not show a significant association between the use of incretin mimetics (fully adjusted HR 1.36, Cl 0.94-1.96) or the use of specific incretin subclasses (DPP-4 inhibitors: fully adjusted HR 1.43, Cl 0.96-2.13; GLP-1 
receptor agonists: fully adjusted $\mathrm{HR} 1.18, \mathrm{Cl} 0.52-2.69)$ with pancreatic cancer, compared with other non-insulin antidiabetic drugs. Notably, a statistically significant increase in risk among incretin users receiving 4-7 prescriptions was observed (fully adjusted HR 1.86, Cl 1.01-3.42), while the risk dropped down in patients receiving more prescriptions (fully adjusted $\mathrm{HR} 0.95, \mathrm{Cl}$ $0.53-1.72) .{ }^{113} \mathrm{~A}$ meta-analysis of 36 double-blind controlled trials on DPP-4 inhibitors versus placebo, with at least 1 year of follow-up and which have enrolled at least $\widehat{500}$ patients, investigating mortality for all causes and cardiovascular death as primary endpoints, did not reported a significant risk for pancreatic cancer (only two trials included in this sub-analysis: SAVOR-TIMI $53^{119} 120$ on sitagliptin and TECOS ${ }^{121}$ on saxagliptin; total events 14 vs 26; RR 0.54, Cl 0.28-1.04). ${ }^{115} \mathrm{~A}$ meta-analysis of 134 trials on DPP-4 inhibitors compared with placebo or active drugs, found no significant risk of pancreatic cancer (OR $0.72, \mathrm{Cl} 0.32-1.61) .{ }^{116} \mathrm{In}$ a populationbased study on Medicare claims data, new users of DPP-4 inhibitors showed a significant reduction in the risk of pancreatic cancer compared with SUs users (HR 0.62, $\mathrm{Cl} 0.41-0.94$ ), and no risk compared with TZDs users (HR 0.97, $\mathrm{Cl} 0.65-1.43$ ). ${ }^{117}$ Of note, the loss of statistically significance after introduction of a 6-month lag period in the sensitivity analysis suggested that the protective effect of DPP-4 inhibitors against SUs likely depended on reverse causality effect or the inclusion of early cancers, for which the causative role of the drug was unlikely (HR 0.73, $\mathrm{Cl} 0.40,1.32){ }^{117}$

\subsection{Risk for medullary thyroid cancer}

A signal of risk of medullary thyroid cancer for exenatide has been pointed out by an analysis of the FDA spontaneous reporting database, ${ }^{109}$ and some evidence suggests a plausible biological rationale for this risk (Box 1). In a pooled analysis of 8 randomized Phase III trials, conducted on patients receiving exenatide once weekly, exenatide twice daily, liraglutide once 
daily and non GLP-1 receptor agonist treatments, the incidence of thyroid benign neoplasms did not differ across groups (0.2, 0.4, 0.5 per 100 patient-years, respectively). ${ }^{114}$ The lack of association between GLP-1 analogues and thyroid cancer was also showed in a meta-analysis of 25 trials conducted on exenatide and liraglutide. ${ }^{122}$

\subsection{Risk for colorectal cancer}

Overall, since GLP-1 receptor is expressed in organs and tissues other than pancreas and thyroid, and since DPP-4 is a multifunctional enzyme cleaving more peptides than just GLP-1, ${ }^{123}$ the potential effects of incretins on proliferation could involve many other anatomical districts (Box 1). The risk of colorectal cancer was investigated in a cohort study of elderly Medicare US patients new-users of DDP-4 inhibitors, in comparison with users of TZDs and SUs, and new users of GLP-1 receptor agonists compared with long acting insulin (LAI). ${ }^{124}$ No significantly increased risk for colorectal cancer was detected for any comparison (DPP-4 inhibitors vs TZDs HR 1.17, Cl 0.88-1.71; DDP-4 inhibitors vs SUs HR 0.98, Cl 0.74-1.30; GLP-1 receptor agonists vs LAI HR 0.82, Cl $0.42-1.58) .{ }^{124}$ Of note, residual confoundings and short follow-up may represent important limitations of this study.

\subsection{Conclusion}

The signal of risk of pancreatic cancer associated with both GLP-1 receptor agonists and DPP-4 inhibitors has substantially not been confirmed in observational studies. However, since the debate remains open, ${ }^{110}{ }^{111}$ further studies, with adequate follow-up periods, would be welcome. Other kinds of cancer (i.e. colonic cancer, thyroid cancer) warrants further investigations. 


\section{Sodium glucose cotransporter 2 (SGLT2) inhibitors}

\subsection{Dapagliflozin and risk for breast and bladder cancer}

Despite pre-clinical experiments have suggested the lack of tumorigenic effects or even anticancer potential (Box 1), initial concerns about the risk of cancer associated with sodium glucose cotransporter 2 (SGLT2) inhibitors were raised during the recent approval of dapagliflozin, the first marketed SGLT2 inhibitor. Indeed, excess numbers of male bladder cancer and female breast cancer were noted in phase $2 \mathrm{~b}$ and phase 3 trials. ${ }^{125-127}$ On the basis of the Surveillance, Epidemiology, and End Results Program and the review of literature about incidence rates of cancer in T2DM, it was concluded that the number of observed bladder and breast cancer in the dapagliflozin-treated patients was higher than the expected number of cases in the general population with T2DM. ${ }^{128}$ Despite the limited number of cases and the lack of statistically significant differences versus comparators, these initial observations led the FDA to suspend dapagliflozin approval. Manufacturers were required to provide more data from ongoing studies and to perform new clinical trials to define the risk-benefit profile of the drug, with particular regard for bladder and breast cancer incidence in the exposed patients. ${ }^{129} 130$ The cancer risk was subsequently re-evaluated and the drug approved by FDA in $2014 .{ }^{131}$ However, updated data from the dapagliflozin clinical development program, based on 21 clinical trials, presented to the FDA in 2013 , showed that there had been a total of 10 cases $(0.15 \%)$ of bladder cancer in patients taking dapagliflozin $(n=6,045)$, compared to 1 case $(0.03 \%)$ of bladder cancer in the control group $(n=3,512)$, with an incidence rate ratio (IRR) of 5.17 (CI 0.68-233.55). For breast cancer, 12 cases $(0.45 \%)$ were reported in patients taking dapagliflozin $(n=2,693)$ compared to $3(0.21 \%)$ cases in the comparator group $(n=1,439)$, with an IRR of 2.47 ( $C l$ 0.64-14.10). Based on these observations, 
the FDA decided to continue the surveillance on the risk of bladder cancer associated with dapagliflozin through the DECLARE TIMI 58 trial. $^{12} 125132133$ In the meantime, the use of dapagliflozin was contraindicated in patients with active bladder cancer and use with caution was advised in patients with history of bladder cancer. Furthermore, as an additional precautionary measure, in Europe dapagliflozin was not recommended in patients concomitantly treated with pioglitazone, considering the increase in the risk of bladder cancer observed in diabetic patients taking this drug. ${ }^{132}$ 134-136

\subsection{Risk for any cancer}

When the risk of cancer was assessed for the other SGLT2 inhibitors, canagliflozin and empagliflozin were not associated with the risk of any cancer in humans. ${ }^{125} 129130137138$ This finding may suggest that, if a risk of bladder cancer exists for dapagligflozin, this is likely not a class effect of SGLT2 inhibitors. ${ }^{125} 134$ Notably, canagliflozin and empagliflozin have been found to induce tumors in rats and mice, but the proposed underlying mechanisms have not been considered relevant for humans. ${ }^{139-142}$ Recently, a post-marketing surveillance study $(n=8,505)$ was performed to investigate the real-world safety of ipragliflozin administered for up to 1 year in elderly Japanese patients with T2DM. Adverse drug reactions (ADRs) associated with malignant tumors included gastric cancer and pancreatic carcinoma (3 cases each, $0.04 \%$ ), colonic cancer and lung neoplasm malignant ( 2 cases each, $0.02 \%$ ), and breast cancer ( 1 case, $0.01 \%$ ). All ADRs related to malignant tumors occurred 45 days after the start of treatment, except for one event with an unknown time of onset. ${ }^{143}$

\subsection{Conclusion}


In recent years, some pooled analyses on dapagliflozin studies have confirmed that the overall incidence of malignancies does not significantly differ in groups of patients exposed or not exposed to dapagliflozin. ${ }^{135} 138142144$ New clinical data suggest that the imbalance of bladder and breast cancer observed with dapagliflozin in early studies might be due to an early diagnosis of preexisting cancer, rather than a real increase in cancer incidence, and to detection biases. ${ }^{138}$ Indeed, it has been suggested that, due to the glycosuria and/or increased symptoms of urinary tract infection, patients taking dapagliflozin likely underwent more urinalyses compared to controls, leading to an easier identification of early stage bladder cancer. Likewise, breast masses were likely better identified in patients on dapagliflozin because of the higher frequency of drugrelated weight loss compared to controls. ${ }^{128}$ Overall, the causal association between bladder cancer and dapagliflozin therapy is yet to be conclusively demonstrated, and the results of the ongoing DECLARE TIMI 58 trial will hopefully provide more definitive evidence. ${ }^{125} 134$

\section{Expert Opinion}

Since T2DM prevalence is expected to further increase in the near future, this disease represents one of the most appealing target for investments by pharmaceutical industries. Therefore, novel antidiabetic drugs will enter the market over the next years. As a consequence, a continuous re-appraisal of older versus newer antidiabetic medications will be required. In particular, the availability of at least equally effective, but safer, new therapeutic options will represent one of the major conditions to decide whether to restrict the prescription of an older drug to specific populations of patients with peculiar clinical features, or even to withdraw that drug from the market. TZDs currently represent a paradigmatic example of the latter situation. 
The present narrative survey highlights the presence of the following pitfalls in the assessment of the safety of antidiabetic medications, with particular regards for cancer-inducing or cancer-protecting effects: a) evidence of increased cancer risk stems mainly from observational studies; b) evaluating the risk of cancer in diabetic patients is challenging due to the complexity of the clinical setting; c) several studies are affected by methodological shortcomings that might lead to inconsistent conclusions. These items represent an important lesson that should encourage a cautionary approach in decision making, while raising three main recommendations.

The first recommendation is for investigators. The performance of observational studies to assess the relationship of antidiabetic drugs use with cancer requires a thorough experience in epidemiology to ensure the necessary methodological quality. Having access to good data does not automatically confers the expertise for performing an analysis. Involving skilled pharmacoepidemiologists is a good starting point for such analyses. Moreover, several studies reviewed in this article evaluated the risk of any cancer associated with the use of an overall drug class. This strategy is likely originated by the will of investigators of constraining the analysis of a rare outcome in a population of patients which is often smaller than that indicated by the sample power estimation. Cancer includes a plethora of both biologically and clinically heterogeneous diseases. This means that investigating the risk of any cancer is a very preliminary and often not informative strategy. Whenever the risk of any cancer is found, subsequent studies should be performed in an attempt of identifying which specific cancers lead the risk. Likewise, tumorigenic effects are not automatically class effects. In this respect, the example of bladder cancer associated with pioglitazone, but not with rosiglitazone, is paradigmatic.

The second recommendation is for journal editors. Editors have the great responsibility of protecting readers from biased results that lead to unreliable conclusions. Biased studies can trigger consequences like that occurred for the putative chemopreventive effect of metformin (i.e. 
stimulating unfruitful investments in clinical trials where patients can be exposed to unnecessary risk to demonstrate a "mirage" benefit). A false risk identified in a biased study can be dangerous as well, since it may jeopardize patient's adherence to therapy. The editor decision about publication should be based on the advice made by qualified experts: it is the qualified reviewer who makes reliable a journal, and not the impact factor!

The third recommendation is for regulatory authorities. Any decision should be taken the evidence originated by good quality studies. Quality assessment of the available evidence should be performed every time a decision regarding the use of a drug is debated. Given the complexity of the clinical setting, this requirement is particularly true for antidiabetic drugs and the risk of cancer, as shown in the present review.

\section{Conclusion}

Evidence supporting the effect of antidiabetic medications on cancer incidence stems mainly from observational studies. Unfortunately, these studies pose methodological challenges and their results are frequently influenced by the effect of limitations that are often intrinsic to the study design and, as such, unavoidable. Accordingly, the available results are often not conclusive, and early evidence of a protection or a risk have not been replicated in subsequent confirmatory studies. Exceptions might be the protective effect of metformin against some kind of malignancies in diabetic patients (although not that protective as shown in some observational study) and the risk of bladder cancer associated with pioglitazone. Although current evidence is reassuring for the majority of antidiabetic medications, research in this field must remain well awaken and active.

\section{Funding}

This paper has not been funded. 


\section{Declaration of interest}

The authors have no relevant affiliations or financial involvement with any organization or entity with a financial interest in or financial conflict with the subject matter or materials discussed in the manuscript. This includes employment, consultancies, honoraria, stock ownership or options, expert testimony, grants or patents received or pending, or royalties. 
Box 1: Summary of the biological rationales propose to account for the cancer promoting or inhibiting actions of antidiabetic drugs

\section{Drug Class \\ Insulin \\ analogues \\ Biological rationale supporting cancer promoting effects \\ Hyperinsulinemia ${ }^{145}$ and overexpression of IGF-1R ${ }^{146147}$ are involved in cancer. The \\ stimulation of IR and IGF-1R by insulin and insulin analogues may promote cell \\ proliferation. ${ }^{148-152}$ Mitogenic effects mediated by IGF-1R have been also observed. \\ ${ }_{153}$ However, there is no firm evidence that insulin can promote malignant transformation of target cells (cancer initiation or mutagenesis). ${ }^{153}$}

\section{Biological rationale supporting cancer-inhibiting effects}

\section{Not reported}

Metformin Not reported

SUs exerts indirect cancer promoting actions mediated by stimulation of insulin release. Insulin binding to IR A, overexpressed in tumor cells, resulting in tumor growth. Insulin also promotes the liver synthesis of IGF-1, which in turn activates IGF-1R on tumor cells with consequent proliferative responses. ${ }^{60}$
Metformin may inhibit mTOR complex 1 in cancer cells, leading to inhibition of mRNA translation, ribosomal biogenesis and cell proliferation. This effect is mediated by the inhibition of pathways downstream to IGF-1 and insulin hormone receptor binding, particularly through the activation of AMPK, which inactivates mTOR both indirectly (TSC2 activation) and directly (mTOR receptor binding). Furthermore, metformin enhances the immune response to cancer cells through a reduction of the immune exhaustion of CD8+ tumor infiltrating lymphocytes. ${ }^{26}$

Glipizide exerts antiangiogenic effects on cancer growth and metastasis through its direct action on endothelial cells. ${ }^{58154}$ Gliclazide exerts antioxidant and antiapoptotic activities. ${ }^{155}$ This drug is endowed with a variety of pharmacological actions: ROS scavenging, the reversible binding to SUR-1, and upregulation of antioxidant enzymes along with reduced mitochondrial alterations $s^{63} 155156$, which have been ascribed to the azabicyclooctyl ring that is unique in gliclazide structure. ${ }^{63} 156$ In addition, gliclazide has been associated with nucleotide excision repair and non-homologous end joining double-strandbreak repair. ${ }^{157}$ Glibenclamide promotes cancer cell death through its interaction with ROS, ${ }^{158} 159$ induces cytostatic effects through cell-cycle arrest in the $G_{0} / G_{1}$ phase, ${ }^{160}$ and contributes to tumor cell damage and apoptosis through $\mathrm{K}^{+}$-ATP channel inhibition. ${ }^{60161162}$ Glibenclamide has been shown to exert inhibitory effects on several cancer cells, including colon and bladder cancer cells. ${ }^{162}$

Glinides Glinides can cause hyperinsulinemia, which increase cancer risk through stimulation of IGF-1, an inducer of cell proliferation and metabolism in several tissues.

Repaglinide can exert antiproliferative effects in hepatocellular carcinoma and cervical cancer cells, but further studies are needed. ${ }^{163}$

An initial long-term study in rats showed an excess of renal tumours at very high doses of acarbose (up to $300 \mathrm{mg} / \mathrm{kg}$ daily). Subsequent studies in rats, hamsters, and dogs suggested that these events were related to carbohydrate malabsorption. In gavage studies, with adequate glucose intake, tumour incidence did not differ in placebo- and acarbose-treated groups. ${ }^{82}$ Glucosidase inhibitors may affect the biosynthesis and structure of oligosaccharides on the cell surface, thus modifying the proliferation of tumour cells, and may suppress the metastatic potential of malignant cells by interference with the synthesis of correct carbohydrate patterns. ${ }^{164}$ Alpha-glucosidase inhibitors are known also to block starch digestion, thus suggesting a decrease in risk for gastric cancer. ${ }^{83}$ Acarbose may increase faecal concentrations of butyrate, a short-chain fatty acid endowed with anticancer effects on colonocytes. ${ }^{165}$ 166 and has been shown to modulate colonic cancer occurrence through a regressive effect on the sizes of adenomas. ${ }^{167}$ 


\section{Drug Class \\ TZDs Biological rationale supporting cancer promoting effects \\ Pioglitazone was found to induce bladder cancer in male rats only, and not in mice} of either sex. ${ }^{168}$ The proposed mechanism, according to which pioglitazone and other PPAR-targeting drugs, namely glitazars, ${ }^{169-171}$ would indirectly stimulate urothelial proliferation through the induction of crystalluria in bladder cannot be excluded $^{169}{ }^{172-174}$ but is unlikely to fully explain the phenomenon. The involvement of PPARY is also debated. Indeed, the little differences observed in the bladder expression of PPARY among genders and species are not consistent with the evidence of a tumor-inducing effect of pioglitazone only in male rats. ${ }^{175}$ Furthermore, rosiglitazone alone did not demonstrate similar effects in rats. ${ }^{176}$ Some authors reported that in the rat urothelium in vivo, PPAR $\alpha$ activation would be responsible for cancer initiation while PPAR $\gamma$ activation supports cancer promotion. ${ }^{177}$ The simultaneous activation of PPAR $\alpha$ and PPARY using a combination of fenofibrate (PPAR $\alpha$ selective agonist) and rosiglitazone (PPAR $y$ selective agonist) was shown to increase the expression of Egr-1 transcription factor, ${ }^{178}$ a potential carcinogenic biomarker. ${ }^{177}$ In this experiment, the use of rosiglitazone or fenofibrate alone did not increase the Egr-1expression. ${ }^{179}$ These two receptors display apparently, a unique co-expression pattern in the urothelium of male compared with female rats, and a similar pattern has been reported in humans. ${ }^{179} 180$ In comparison with rosiglitazone, Pioglitazone is less selective for PPARy, and it has a residual activity toward PPAR $\alpha{ }^{181}{ }^{182}$ This pattern would explain the different tumorigenic potential of pioglitazone and rosiglitazone as well as the cancerogenic similarity of pioglitazone with glitazars. $\begin{array}{ll}\text { Incretin } & \text { GLP-1R agonists stimulate calcitonin secretion and promotes C-cell hyperplasia and } \\ \text { mimetics } & \text { medullary thyroid cancer in rodents. This species-specific observation is dose- }\end{array}$ dependent and associated with GLP-1R agonists only. ${ }^{188-191}$ GLP-1R stimulation may induce cell proliferation and neoplastic transformation activating the PI3K signaling pathway. ${ }^{192} 193$ Changes in the expression and activity of DPP-4 have been described for malignancies such as colon cancer, ${ }^{194}$ ovarian carcinoma ${ }_{195}$ cervical cancer, ${ }^{196} 197$ endometrial adenocarcinoma, ${ }^{198}{ }^{199}{ }^{\prime}$ and prostate cancer. ${ }^{200} 201$ Loss of DPP-4 activity results in more aggressive tumour features and higher metastatic grade. 195198200202

\section{Biological rationale supporting cancer-inhibiting effects}

TZDs can exert PPAR $\gamma$-dependent ${ }^{183184185186}$ and PPAR $\gamma$-independent antitumor effects, ${ }^{187}$ which seem

to be dose-dependent, as well as cell-, species-, and compound-specific. ${ }^{183}$

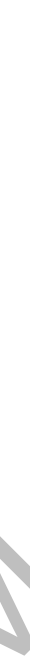

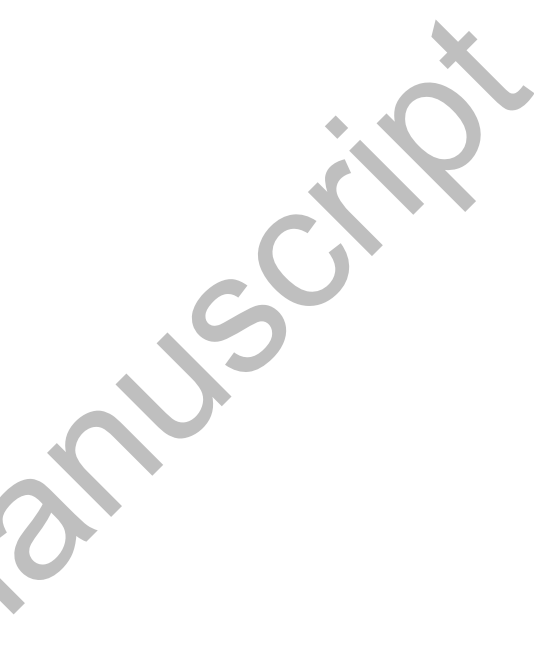

Liraglutide, through GLP-1R activation, can exert inhibitory effects on human pancreatic cancer cells via $\mathrm{PI}$ I3K/Akt pathway. ${ }^{203}$ Some studies have shown a potential anticancer activity for sitagliptin and vildagliptin in colorectal cancer cells, ${ }^{204}$ as well as for sitagliptin in breast and cervical cancer cell lines. ${ }^{197}$ ${ }^{205}$ In rodent pre-clinical studies, an anti-tumour effect has been described for vildagliptin in colorectal lung metastases, ${ }^{206}$ and for sitagliptin in colon cancer. ${ }^{207}$ Exendin-4 (exenatide analogue) reduces cell migration in neuroblastoma cell lines ${ }^{208}$ and attenuates neoplastic cell growth through ERK-MAPK inhibition in prostate cancer, ${ }^{209}$ with an enhancing effect when the treatment is combined with metformin. $^{210}$

SGLT2 inhibitors suppress glucose uptake, thus reducing tumor growth and survival, through a limitation of glucose availability. ${ }^{211}$ Canagliflozin, but not dapagliflozin, inhibits cellular proliferation and clonogenic survival of prostate and lung cancer cells, alone or in combination with ionizing radiation or chemotherapy with docetaxel. ${ }^{212}$ In mice bearing tumor xenographs, both dapagliflozin and canagliflozin increased tumour necrosis and delayed tumor growth, either alone or in combination with cytostatic therapy. ${ }^{213}$ 


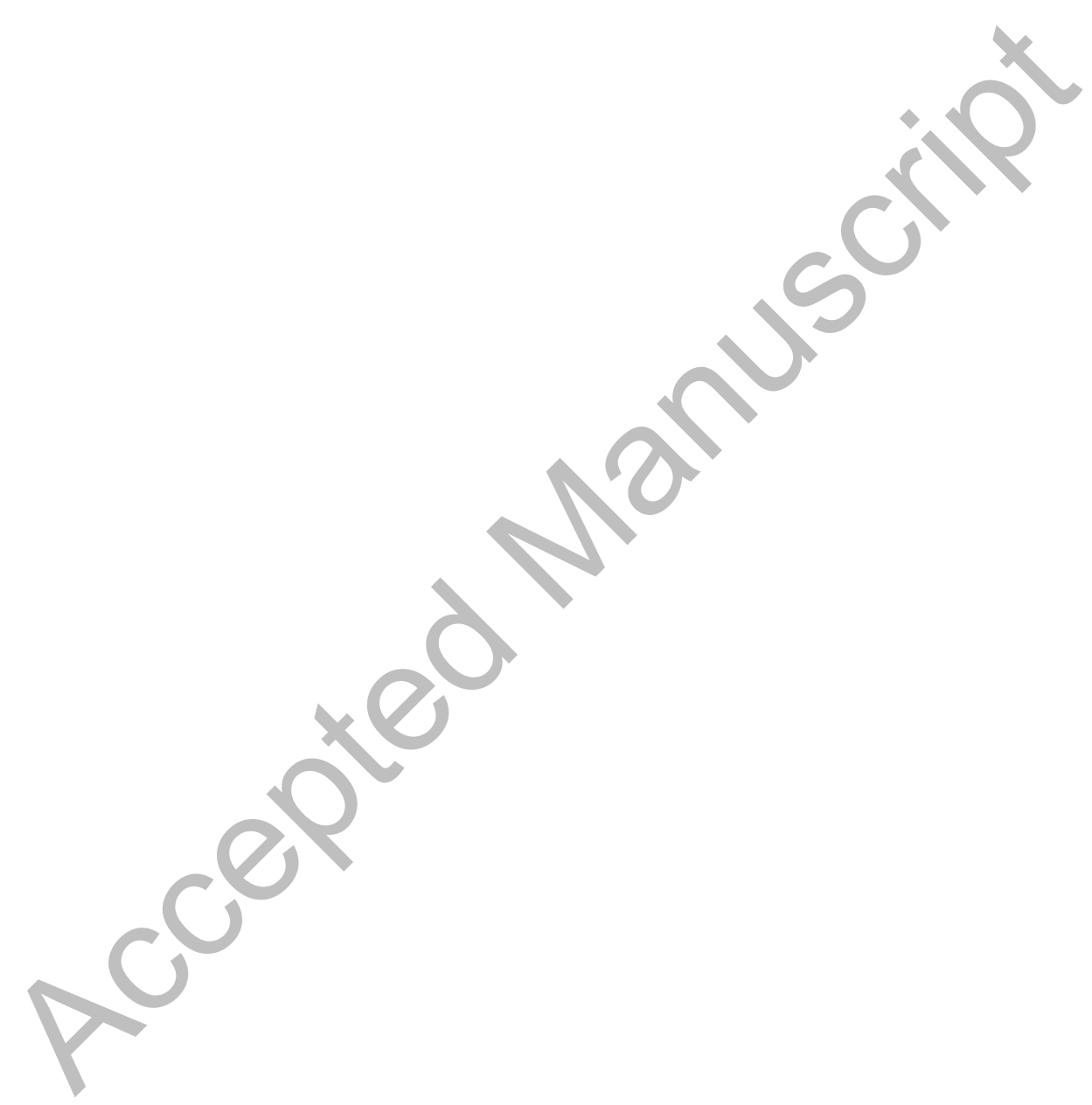




\section{References}

\section{Papers of special note have been highlighted as: ${ }^{*}$ of interest ${ }^{* *}$ of considerable interest}

1. Lutz SZ, Staiger H, Fritsche A, et al. Antihyperglycaemic therapies and cancer risk. Diab Vasc Dis Res 2014;11(6):371-89.

2. Klil-Drori AJ, Azoulay L, Pollak MN. Cancer, obesity, diabetes, and antidiabetic drugs: is the fog clearing? Nat Rev Clin Oncol 2017;14(2):85-99.

3. Luo J, Chlebowski R, Liu S, et al. Diabetes mellitus as a risk factor for gastrointestinal cancers among postmenopausal women. Cancer causes \& control : CCC 2013;24(3):577-85.

4. Suissa S, Azoulay L. Metformin and the risk of cancer: time-related biases in observational studies. Diabetes care 2012;35(12):2665-73.

5. Colhoun HM. Use of insulin glargine and cancer incidence in Scotland: a study from the Scottish Diabetes Research Network Epidemiology Group. Diabetologia 2009;52(9):1755-65.

6. Hemkens LG, Grouven U, Bender R, et al. Risk of malignancies in patients with diabetes treated with human insulin or insulin analogues: a cohort study. Diabetologia 2009;52(9):1732-44.

7. Currie CJ, Poole CD, Gale EA. The influence of glucose-lowering therapies on cancer risk in type 2 diabetes. Diabetologia 2009;52(9):1766-77.

8. Jonasson JM, Ljung $R$, Talback $M$, et al. Insulin glargine use and short-term incidence of malignancies-a population-based follow-up study in Sweden. Diabetologia 2009;52(9):1745-54.

9. Mannucci E, Monami M, Balzi D, et al. Doses of insulin and its analogues and cancer occurrence in insulin-treated type 2 diabetic patients. Diabetes care 2010;33(9):1997-2003.

10. Karlstad O, Starup-Linde J, Vestergaard P, et al. Use of insulin and insulin analogs and risk of cancer systematic review and meta-analysis of observational studies. Current drug safety 2013;8(5):33348.

11. Home P. Insulin therapy and cancer. Diabetes care 2013;36 Suppl 2:S240-4.

12. Sturmer T, Marquis MA, Zhou H, et al. Cancer incidence among those initiating insulin therapy with glargine versus human NPH insulin. Diabetes care 2013;36(11):3517-25.

13. Du $X$, Zhang $R$, Xue $Y$, et al. Insulin glargine and risk of cancer: a meta-analysis. The International journal of biological markers 2012;27(3):e241-6.

14. Home PD, Lagarenne P. Combined randomised controlled trial experience of malignancies in studies using insulin glargine. Diabetologia 2009;52(12):2499-506.

15. Tang $X$, Yang $L, H e Z$, et al. Insulin glargine and cancer risk in patients with diabetes: a meta-analysis. PloS one 2012;7(12):e51814.

16. Cardiovascular and Other Outcomes Postintervention With Insulin Glargine and Omega-3 Fatty Acids (ORIGINALE). Diabetes care 2016;39(5):709-16.

17. Ljung R, Talback M, Haglund B, et al. Insulin glargine use and short-term incidence of malignancies - a three-year population-based observation. Acta oncologica (Stockholm, Sweden) 2011;50(5):685-93.

18. Ruiter R, Visser LE, van Herk-Sukel MP, et al. Risk of cancer in patients on insulin glargine and other insulin analogues in comparison with those on human insulin: results from a large population-based follow-up study. Diabetologia 2012;55(1):51-62.

19. Grimaldi-Bensouda L, Cameron D, Marty M, et al. Risk of breast cancer by individual insulin use: an international multicenter study. Diabetes care 2014;37(1):134-43.

20. Suissa S, Azoulay L, Dell'Aniello S, et al. Long-term effects of insulin glargine on the risk of breast cancer. Diabetologia 2011;54(9):2254-62.

21. Habel LA, Danforth KN, Quesenberry CP, et al. Cohort study of insulin glargine and risk of breast, prostate, and colorectal cancer among patients with diabetes. Diabetes care 2013;36(12):3953-60.

22. Bronsveld HK, ter Braak B, Karlstad O, et al. Treatment with insulin (analogues) and breast cancer risk in diabetics; a systematic review and meta-analysis of in vitro, animal and human evidence. Breast cancer research : BCR 2015;17:100.

23. Colmers IN, Bowker SL, Tjosvold LA, et al. Insulin use and cancer risk in patients with type 2 diabetes: a systematic review and meta-analysis of observational studies. Diabetes $\&$ metabolism 2012;38(6):485-506. 
24. Wu JW, Filion KB, Azoulay L, et al. Effect of Long-Acting Insulin Analogs on the Risk of Cancer: A Systematic Review of Observational Studies. Diabetes care 2016;39(3):486-94.

25. Evans JM, Donnelly LA, Emslie-Smith AM, et al. Metformin and reduced risk of cancer in diabetic patients. BMJ (Clinical research ed) 2005;330(7503):1304-5.

26. Chae YK, Arya A, Malecek MK, et al. Repurposing metformin for cancer treatment: current clinical studies. Oncotarget 2016;7(26):40767-80.

27. Decensi A, Puntoni M, Goodwin P, et al. Metformin and cancer risk in diabetic patients: a systematic review and meta-analysis. Cancer prevention research (Philadelphia, $\mathrm{Pa}$ ) 2010;3(11):1451-61.

28. Libby G, Donnelly LA, Donnan PT, et al. New users of metformin are at low risk of incident cancer: a cohort study among people with type 2 diabetes. Diabetes care 2009;32(9):1620-5.

29. Noto H, Goto A, Tsujimoto T, et al. Cancer risk in diabetic patients treated with metformin: a systematic review and meta-analysis. PloS one 2012;7(3):e33411.

30. Bodmer M, Meier C, Krahenbuhl S, et al. Long-term metformin use is associated with decreased risk of breast cancer. Diabetes care 2010;33(6):1304-8.

31. Gandini S, Puntoni M, Heckman-Stoddard BM, et al. Metformin and cancer risk and mortality: a systematic review and meta-analysis taking into account biases and confounders. Cancer prevention research (Philadelphia, Pa) 2014;7(9):867-85.

32. Kowall B, Stang A, Rathmann W, et al. No reduced risk of overall, colorectal, lung, breast, and prostate cancer with metformin therapy in diabetic patients: database analyses from Germany and the UK. Pharmacoepidemiology and drug safety 2015;24(8):865-74.

33. de Jong RG, Burden AM, de Kort $S$, et al. No decreased risk of gastrointestinal cancers in users of metformin in The Netherlands; a time-varying analysis of metformin exposure. Cancer prevention research (Philadelphia, Pa) 2017.

34. Frouws MA, Mulder BG, Bastiaannet $E$, et al. No association between metformin use and survival in patients with pancreatic cancer: An observational cohort study. Medicine 2017;96(10):e6229.

35. Becker C, Jick SS, Meier CR, et al. No evidence for a decreased risk of thyroid cancer in association with use of metformin or other antidiabetic drugs: a case-control study. BMC cancer 2015;15:719.

36. Becker C, Jick SS, Meier CR, et al. Metformin and the risk of renal cell carcinoma: a case-control analysis. European journal of cancer prevention : the official journal of the European Cancer Prevention Organisation (ECP) 2017;26(3):257-62.

37. Bodmer M, Becker C, Meier C, et al. Use of metformin and the risk of ovarian cancer: a case-control analysis. Gynecologic oncology 2011;123(2):200-4.

38. Bodmer M, Becker C, Meier C, et al. Use of metformin is not associated with a decreased risk of colorectal cancer: a case-control analysis. Cancer epidemiology, biomarkers \& prevention : a publication of the American Association for Cancer Research, cosponsored by the American Society of Preventive Oncology 2012;21(2):280-6.

39. Bodmer M, Becker C, Jick SS, et al. Metformin does not alter the risk of lung cancer: a case-control analysis. Lung cancer (Amsterdam, Netherlands) 2012;78(2):133-7.

40. Becker C, Jick SS, Meier CR, et al. Metformin and the risk of endometrial cancer: a case-control analysis. Gynecologic oncology 2013;129(3):565-9.

41. Becker C, Meier CR, Jick SS, et al. Case-control analysis on metformin and cancer of the esophagus. Cancer causes \& control : CCC 2013;24(10):1763-70.

42. Hagberg KW, McGlynn KA, Sahasrabuddhe VV, et al. Anti-diabetic medications and risk of primary liver cancer in persons with type II diabetes. British journal of cancer 2014;111(9):1710-7.

43. Heckman-Stoddard BM, Gandini S, Puntoni M, et al. Repurposing old drugs to chemoprevention: the case of metformin. Seminars in oncology 2016;43(1):123-33.

44. Braghiroli MI, de Celis Ferrari AC, Pfiffer TE, et al. Phase II trial of metformin and paclitaxel for patients with gemcitabine-refractory advanced adenocarcinoma of the pancreas. Ecancermedicalscience 2015;9:563.

45. Kordes S, Pollak MN, Zwinderman AH, et al. Metformin in patients with advanced pancreatic cancer: a double-blind, randomised, placebo-controlled phase 2 trial. The Lancet Oncology 2015;16(7):83947. 
46. Reni M, Dugnani E, Cereda S, et al. (Ir)relevance of Metformin Treatment in Patients with Metastatic Pancreatic Cancer: An Open-Label, Randomized Phase II Trial. Clinical cancer research : an official journal of the American Association for Cancer Research 2016;22(5):1076-85.

47. Goodwin PJ, Parulekar WR, Gelmon KA, et al. Effect of metformin vs placebo on and metabolic factors in NCIC CTG MA.32. Journal of the National Cancer Institute 2015;107(3).

48. Suissa S. Metformin to Treat Cancer: Misstep in Translational Research from Observational Studies. Epidemiology (Cambridge, Mass) 2017.

49. Tuccori M, Wu JW, Yin H, et al. The Use of Glyburide Compared With Other Sulfonylureas and the Risk of Cancer in Patients With Type 2 Diabetes. Diabetes Care 2015;38(11):2083-9.

50. Hong JL, Funk MJ, Buse J, et al. Comparative effect of Initiating Metformin versus Sulfonylureas on Breast Cancer Risk in Older Women. Epidemiology 2017.

51. Bowker SL, Lin M, Eurich DT, et al. Time-Varying Risk for Breast Cancer Following Initiation of GlucoseLowering Therapy in Women with Type 2 Diabetes: Exploring Detection Bias. Can J Diabetes 2016.

52. Calip GS, Yu O, Elmore JG, et al. Comparative safety of diabetes medications and risk of incident invasive breast cancer: a population-based cohort study. Cancer Causes Control 2016;27(5):709-20.

53. Haggstrom C, Van Hemelrijck M, Zethelius B, et al. Prospective study of Type 2 diabetes mellitus, antidiabetic drugs and risk of prostate cancer. Int J Cancer 2017;140(3):611-17.

54. Jayalath VH, Ireland C, Fleshner NE, et al. The Relationship Between Metformin and Serum ProstateSpecific Antigen Levels. Prostate 2016;76(15):1445-53.

55. Chen YC, Kok VC, Chien CH, et al. Cancer risk in patients aged 30 years and above with type 2 diabetes receiving antidiabetic monotherapy: a cohort study using metformin as the comparator. Therapeutics and clinical risk management 2015;11:1315-23.

56. Singh S, Singh H, Singh PP, et al. Antidiabetic medications and the risk of colorectal cancer in patients with diabetes mellitus: a systematic review and meta-analysis. Cancer Epidemiol Biomarkers Prev 2013;22(12):2258-68.

57. Cheng KC, Chen YL, Lai SW, et al. Risk of esophagus cancer in diabetes mellitus: a population-based case-control study in Taiwan. BMC Gastroenterol 2012;12:177.

58. Lu Y, Garcia Rodriguez LA, Malgerud L, et al. New-onset type 2 diabetes, elevated HbA1c, anti-diabetic medications, and risk of pancreatic cancer. Br J Cancer 2015;113(11):1607-14.

59. Kowall B, Rathmann W, Kostev K. Are sulfonylurea and insulin therapies associated with a larger risk of cancer than metformin therapy? A retrospective database analysis. Diabetes Care 2015;38(1):5965.

60. Chen Y, Du L, Li L, et al. Cancer risk of sulfonylureas in patients with type 2 diabetes mellitus: A systematic review. J Diabetes 2016.

61. Wu L, Zhu J, Prokop LJ, et al. Pharmacologic Therapy of Diabetes and Overall Cancer Risk and Mortality: A Meta-Analysis of 265 Studies. Scientific reports 2015;5:10147.

62. Vissers PA, Cardwell CR, van de Poll-Franse LV, et al. The association between glucose-lowering drug use and mortality among breast cancer patients with type 2 diabetes. Breast Cancer Res Treat 2015;150(2):427-37.

63. Bo S, Castiglione A, Ghigo E, et al. Mortality outcomes of different sulphonylurea drugs: the results of a 14-year cohort study of type 2 diabetic patients. Eur J Endocrinol 2013;169(1):117-26.

64. Monami M, Lamanna C, Balzi D, et al. Sulphonylureas and cancer: a case-control study. Acta Diabetol 2009;46(4):279-84.

65. Qiu H, Rhoads GG, Berlin JA, et al. Initial metformin or sulphonylurea exposure and cancer occurrence among patients with type 2 diabetes mellitus. Diabetes, obesity \& metabolism 2013;15(4):349-57.

66. Chang CH, Lin JW, Wu LC, et al. Oral insulin secretagogues, insulin, and cancer risk in type 2 diabetes mellitus. The Journal of clinical endocrinology and metabolism 2012;97(7):E1170-5.

67. Simo R, Plana-Ripoll O, Puente D, et al. Impact of glucose-lowering agents on the risk of cancer in type 2 diabetic patients. The Barcelona case-control study. PLoS One 2013;8(11):e79968.

68. Sun GE, Wells BJ, Yip K, et al. Gender-specific effects of oral hypoglycaemic agents on cancer risk in type 2 diabetes mellitus. Diabetes, obesity \& metabolism 2014;16(3):276-83. 
69. Franchi M, Asciutto R, Nicotra F, et al. Metformin, other antidiabetic drugs, and endometrial cancer risk: a nested case-control study within Italian healthcare utilization databases. European journal of cancer prevention : the official journal of the European Cancer Prevention Organisation (ECP) 2016.

70. Goossens ME, Buntinx F, Zeegers MP, et al. Influence of metformin intake on the risk of bladder cancer in type 2 diabetes patients. British journal of clinical pharmacology 2015;80(6):1464-72.

71. Chen YL, Cheng KC, Lai SW, et al. Diabetes and risk of subsequent gastric cancer: a population-based cohort study in Taiwan. Gastric Cancer 2013;16(3):389-96.

72. Lin CM, Huang HL, Chu FY, et al. Association between Gastroenterological Malignancy and Diabetes Mellitus and Anti-Diabetic Therapy: A Nationwide, Population-Based Cohort Study. PLoS One 2015;10(5):e0125421.

73. Chiu CC, Huang CC, Chen YC, et al. Increased risk of gastrointestinal malignancy in patients with diabetes mellitus and correlations with anti-diabetes drugs: a nationwide population-based study in Taiwan. Intern Med 2013;52(9):939-46.

74. Chang $\mathrm{CH}$, Lin JW, Wu LC, et al. Association of thiazolidinediones with liver cancer and colorectal cancer in type 2 diabetes mellitus. Hepatology (Baltimore, Md) 2012;55(5):1462-72.

75. Bosetti C, Franchi M, Nicotra F, et al. Insulin and other antidiabetic drugs and hepatocellular carcinoma risk: a nested case-control study based on Italian healthcare utilization databases.

Pharmacoepidemiology and drug safety 2015;24(7):771-8.

76. Tseng YH, Tsan YT, Chan WC, et al. Use of an alpha-Glucosidase Inhibitor and the Risk of Colorectal Cancer in Patients With Diabetes: A Nationwide, Population-Based Cohort Study. Diabetes Care 2015;38(11):2068-74.

77. Lai SW, Liao KF, Lai HC, et al. Kidney cancer and diabetes mellitus: a population-based case-control study in Taiwan. Ann Acad Med Singapore 2013;42(3):120-4.

78. Tseng $\mathrm{CH}$. Diabetes, metformin use, and colon cancer: a population-based cohort study in Taiwan. Eur J Endocrinol 2012;167(3):409-16.

79. Lai SW, Liao KF, Chen PC, et al. Antidiabetes drugs correlate with decreased risk of lung cancer: a population-based observation in Taiwan. Clin Lung Cancer 2012;13(2):143-8.

80. Tseng $\mathrm{CH}$. Diabetes and risk of bladder cancer: a study using the National Health Insurance database in Taiwan. Diabetologia 2011;54(8):2009-15.

81. Tseng CH. Thyroid cancer risk is not increased in diabetic patients. PLoS One 2012;7(12):e53096.

82. Hollander P. Safety profile of acarbose, an alpha-glucosidase inhibitor. Drugs 1992;44 Suppl 3:47-53.

83. De Stefani E, Deneo-Pellegrini $H$, Boffetta $P$, et al. Dietary patterns and risk of cancer: a factor analysis in Uruguay. International journal of cancer 2009;124(6):1391-7.

84. Starner $\mathrm{Cl}$, Schafer JA, Heaton $\mathrm{AH}$, et al. Rosiglitazone and pioglitazone utilization from January 2007 through May 2008 associated with five risk-warning events. Journal of managed care pharmacy : JMCP 2008;14(6):523-31.

85. Monami M, Dicembrini I, Mannucci E. Thiazolidinediones and cancer: results of a meta-analysis of randomized clinical trials. Acta Diabetol 2014;51(1):91-101.

86. Bosetti C, Rosato V, Buniato D, et al. Cancer risk for patients using thiazolidinediones for type 2 diabetes: a meta-analysis. Oncologist 2013;18(2):148-56.

87. Singh S, Singh PP, Singh AG, et al. Anti-diabetic medications and the risk of hepatocellular cancer: a systematic review and meta-analysis. Am J Gastroenterol 2013;108(6):881-91; quiz 92.

88. Bergvall T, Noren GN, Lindquist M. vigiGrade: a tool to identify well-documented individual case reports and highlight systematic data quality issues. Drug safety 2014;37(1):65-77.

89. Suissa S. Immortal time bias in pharmaco-epidemiology. American journal of epidemiology 2008;167(4):492-9.

90. Dormandy JA, Charbonnel B, Eckland DJ, et al. Secondary prevention of macrovascular events in patients with type 2 diabetes in the PROactive Study (PROspective pioglitAzone Clinical Trial In macroVascular Events): a randomised controlled trial. Lancet 2005;366(9493):1279-89.

91. Kung J, Henry RR. Thiazolidinedione safety. Expert Opin Drug Saf 2012;11(4):565-79.

92. Turner RM, Kwok CS, Chen-Turner C, et al. Thiazolidinediones and associated risk of bladder cancer: a systematic review and meta-analysis. Br J Clin Pharmacol 2014;78(2):258-73. 
93. Hsiao FY, Hsieh PH, Huang WF, et al. Risk of bladder cancer in diabetic patients treated with rosiglitazone or pioglitazone: a nested case-control study. Drug Saf 2013;36(8):643-9.

94. Fujimoto K, Hamamoto Y, Honjo S, et al. Possible link of pioglitazone with bladder cancer in Japanese patients with type 2 diabetes. Diabetes Res Clin Pract 2013;99(2):e21-3.

95. Jin SM, Song SO, Jung $\mathrm{CH}$, et al. Risk of bladder cancer among patients with diabetes treated with a 15 mg pioglitazone dose in Korea: a multi-center retrospective cohort study. J Korean Med Sci 2014;29(2):238-42.

96. Wei L, MacDonald TM, Mackenzie IS. Pioglitazone and bladder cancer: a propensity score matched cohort study. Br J Clin Pharmacol 2013;75(1):254-9.

97. Vallarino C, Perez A, Fusco G, et al. Comparing pioglitazone to insulin with respect to cancer, cardiovascular and bone fracture endpoints, using propensity score weights. Clin Drug Investig 2013;33(9):621-31.

98. Balaji V, Seshiah V, Ashtalakshmi G, et al. A retrospective study on finding correlation of pioglitazone and incidences of bladder cancer in the Indian population. Indian J Endocrinol Metab 2014;18(3):425-7.

99. Kuo HW, Tiao MM, Ho SC, et al. Pioglitazone use and the risk of bladder cancer. Kaohsiung J Med Sci 2014;30(2):94-7.

100. Lee MY, Hsiao PJ, Yang YH, et al. The association of pioglitazone and urinary tract disease in type 2 diabetic Taiwanese: bladder cancer and chronic kidney disease. PLoS One 2014;9(1):e85479.

101. Levin D, Bell S, Sund R, et al. Pioglitazone and bladder cancer risk: a multipopulation pooled, cumulative exposure analysis. Diabetologia 2015;58(3):493-504.

102. Lewis JD, Ferrara A, Peng T, et al. Risk of bladder cancer among diabetic patients treated with pioglitazone: interim report of a longitudinal cohort study. Diabetes Care 2011;34(4):916-22.

103. Lewis JD, Habel LA, Quesenberry CP, et al. Pioglitazone Use and Risk of Bladder Cancer and Other Common Cancers in Persons With Diabetes. JAMA 2015;314(3):265-77.

104. Korhonen P, Heintjes EM, Williams R, et al. Pioglitazone use and risk of bladder cancer in patients with type 2 diabetes: retrospective cohort study using datasets from four European countries. BMJ 2016;354:i3903.

105. Boxall N, Bennett D, Hunger M, et al. Evaluation of exposure to pioglitazone and risk of prostate cancer: a nested case-control study. BMJ Open Diabetes Res Care 2016;4(1):e000303.

106. Tuccori M, Filion KB, Yin $\mathrm{H}$, et al. Pioglitazone use and risk of bladder cancer: population based cohort study. BMJ 2016;352:i1541.

107. http://www.ema.europa.eu/docs/en GB/document library/EPAR Product Information/human/002277/WC500126042.pdf.

108. http://www.fda.gov/Drugs/DrugSafety/ucm266555.htm.

109. Elashoff M, Matveyenko AV, Gier B, et al. Pancreatitis, pancreatic, and thyroid cancer with glucagonlike peptide-1-based therapies. Gastroenterology 2011;141(1):150-6.

110. Egan AG, Blind E, Dunder K, et al. Pancreatic safety of incretin-based drugs--FDA and EMA assessment. N Engl J Med 2014;370(9):794-7.

111. Nagel AK, Ahmed-Sarwar N, Werner PM, et al. Dipeptidyl Peptidase-4 Inhibitor-Associated Pancreatic Carcinoma: A Review of the FAERS Database. Ann Pharmacother 2016;50(1):27-31.

112. Tseng CM, Liao WC, Chang CY, et al. Incretin-based pharmacotherapy and risk of adverse pancreatic events in the ethnic Chinese with diabetes mellitus: A population-based study in Taiwan. Pancreatology 2017;17(1):76-82.

113. Knapen LM, van Dalem J, Keulemans YC, et al. Use of incretin agents and risk of pancreatic cancer: a population-based cohort study. Diabetes Obes Metab 2016;18(3):258-65.

114. MacConell L, Gurney K, Malloy J, et al. Safety and tolerability of exenatide once weekly in patients with type 2 diabetes: an integrated analysis of 4,328 patients. Diabetes Metab Syndr Obes 2015;8:24153.

115. Rehman MB, Tudrej BV, Soustre J, et al. Efficacy and safety of DPP-4 inhibitors in patients with type 2 diabetes: Meta-analysis of placebo-controlled randomized clinical trials. Diabetes Metab 2017;43(1):48-58. 
116. Monami M, Dicembrini I, Mannucci E. Dipeptidyl peptidase-4 inhibitors and pancreatitis risk: a metaanalysis of randomized clinical trials. Diabetes Obes Metab 2014;16(1):48-56.

117. Gokhale M, Buse JB, Gray CL, et al. Dipeptidyl-peptidase-4 inhibitors and pancreatic cancer: a cohort study. Diabetes Obes Metab 2014;16(12):1247-56.

118. Azoulay L, Filion KB, Platt RW, et al. Incretin based drugs and the risk of pancreatic cancer: international multicentre cohort study. Bmj 2016;352:i581.

119. Scirica BM, Bhatt DL, Braunwald E, et al. Saxagliptin and cardiovascular outcomes in patients with type 2 diabetes mellitus. N Engl J Med 2013;369(14):1317-26.

120. Raz I, Bhatt DL, Hirshberg B, et al. Incidence of pancreatitis and pancreatic cancer in a randomized controlled multicenter trial (SAVOR-TIMI 53) of the dipeptidyl peptidase-4 inhibitor saxagliptin. Diabetes Care 2014;37(9):2435-41.

121. Green JB, Bethel MA, Armstrong PW, et al. Effect of Sitagliptin on Cardiovascular Outcomes in Type 2 Diabetes. N Engl J Med 2015;373(3):232-42.

122. Alves C, Batel-Marques F, Macedo AF. A meta-analysis of serious adverse events reported with exenatide and liraglutide: acute pancreatitis and cancer. Diabetes research and clinical practice 2012;98(2):271-84.

123. Drucker DJ. The biology of incretin hormones. Cell Metab 2006;3(3):153-65.

124. Htoo PT, Buse JB, Gokhale M, et al. Effect of glucagon-like peptide-1 receptor agonists and dipeptidyl peptidase-4 inhibitors on colorectal cancer incidence and its precursors. Eur J Clin Pharmacol 2016;72(8):1013-23.

125. Lin HW, Tseng CH. A Review on the Relationship between SGLT2 Inhibitors and Cancer. Int J Endocrinol 2014;2014:719578.

126. Monica Reddy RP, Inzucchi SE. SGLT2 inhibitors in the management of type 2 diabetes. Endocrine 2016;53(2):364-72.

127. Rosenwasser RF, Sultan S, Sutton D, et al. SGLT-2 inhibitors and their potential in the treatment of diabetes. Diabetes Metab Syndr Obes 2013;6:453-67.

128. Kim Y, Babu AR. Clinical potential of sodium-glucose cotransporter 2 inhibitors in the management of type 2 diabetes. Diabetes Metab Syndr Obes 2012;5:313-27.

129. Vasilakou D, Karagiannis T, Athanasiadou E, et al. Sodium-glucose cotransporter 2 inhibitors for type 2 diabetes: a systematic review and meta-analysis. Ann Intern Med 2013;159(4):262-74.

130. Riser Taylor S, Harris KB. The clinical efficacy and safety of sodium glucose cotransporter-2 inhibitors in adults with type 2 diabetes mellitus. Pharmacotherapy 2013;33(9):984-99.

131. Saeed MA, Narendran P. Dapagliflozin for the treatment of type 2 diabetes: a review of the literature. Drug Des Devel Ther 2014;8:2493-505.

132. Kuecker CM, Vivian EM. Patient considerations in type 2 diabetes - role of combination dapagliflozinmetformin XR. Diabetes Metab Syndr Obes 2016;9:25-35.

133. Vivian EM. Dapagliflozin: a new sodium-glucose cotransporter 2 inhibitor for treatment of type 2 diabetes. Am J Health Syst Pharm 2015;72(5):361-72.

134. Kalra S, Ghosh S, Aamir AH, et al. Safe and pragmatic use of sodium-glucose co-transporter 2 inhibitors in type 2 diabetes mellitus: South Asian Federation of Endocrine Societies consensus statement. Indian J Endocrinol Metab 2017;21(1):210-30.

135. Parikh S, Wilding J, Jabbour S, et al. Dapagliflozin in type 2 diabetes: effectiveness across the spectrum of disease and over time. Int J Clin Pract 2015;69(2):186-98.

136. Hinnen D. Glucuretic effects and renal safety of dapagliflozin in patients with type 2 diabetes. Ther Adv Endocrinol Metab 2015;6(3):92-102.

137. Kohler S, Salsali A, Hantel S, et al. Safety and Tolerability of Empagliflozin in Patients with Type 2 Diabetes. Clin Ther 2016;38(6):1299-313.

138. Scheen AJ. SGLT2 Inhibitors: Benefit/Risk Balance. Curr Diab Rep 2016;16(10):92.

139. Bogdanffy MS, Stachlewitz RF, van Tongeren S, et al. Nonclinical safety of the sodium-glucose cotransporter 2 inhibitor empagliflozin. Int J Toxicol 2014;33(6):436-49.

140. De Jonghe S, Proctor J, Vinken P, et al. Carcinogenicity in rats of the SGLT2 inhibitor canagliflozin. Chem Biol Interact 2014;224:1-12. 
141. Taub ME, Ludwig-Schwellinger E, Ishiguro N, et al. Sex-, Species-, and Tissue-Specific Metabolism of Empagliflozin in Male Mouse Kidney Forms an Unstable Hemiacetal Metabolite (M466/2) That Degrades to 4-Hydroxycrotonaldehyde, a Reactive and Cytotoxic Species. Chem Res Toxicol 2015;28(1):103-15.

142. Ptaszynska A, Cohen SM, Messing EM, et al. Assessing Bladder Cancer Risk in Type 2 Diabetes Clinical Trials: the Dapagliflozin Drug Development Program as a 'Case Study'. Diabetes Ther 2015;6(3):35775.

143. Yokote K, Terauchi Y, Nakamura I, et al. Real-world evidence for the safety of ipragliflozin in elderly Japanese patients with type 2 diabetes mellitus (STELLA-ELDER): final results of a post-marketing surveillance study. Expert Opin Pharmacother 2016;17(15):1995-2003.

144. Ptaszynska A, Johnsson KM, Parikh SJ, et al. Safety profile of dapagliflozin for type 2 diabetes: pooled analysis of clinical studies for overall safety and rare events. Drug Saf 2014;37(10):815-29.

145. LeRoith D, Novosyadlyy R, Gallagher EJ, et al. Obesity and type 2 diabetes are associated with an increased risk of developing cancer and a worse prognosis; epidemiological and mechanistic evidence. Experimental and clinical endocrinology \& diabetes : official journal, German Society of Endocrinology [and] German Diabetes Association 2008;116 Suppl 1:S4-6.

146. Vella V, Pandini G, Sciacca L, et al. A novel autocrine loop involving IGF-Il and the insulin receptor isoform-A stimulates growth of thyroid cancer. The Journal of clinical endocrinology and metabolism 2002;87(1):245-54.

147. Heni M, Hennenlotter J, Scharpf $M$, et al. Insulin receptor isoforms A and B as well as insulin receptor substrates-1 and -2 are differentially expressed in prostate cancer. PloS one 2012;7(12):e50953.

148. Gallagher EJ, Alikhani N, Tobin-Hess A, et al. Insulin receptor phosphorylation by endogenous insulin or the insulin analog AspB10 promotes mammary tumor growth independent of the IGF-I receptor. Diabetes 2013;62(10):3553-60.

149. Singh P, Alex JM, Bast F. Insulin receptor (IR) and insulin-like growth factor receptor 1 (IGF-1R) signaling systems: novel treatment strategies for cancer. Medical oncology (Northwood, London, England) 2014;31(1):805.

150. Draznin B. Mitogenic action of insulin: friend, foe or 'frenemy'? Diabetologia 2010;53(2):229-33.

151. Kurtzhals P, Schaffer L, Sorensen A, et al. Correlations of receptor binding and metabolic and mitogenic potencies of insulin analogs designed for clinical use. Diabetes 2000;49(6):999-1005.

152. Sciacca L, Cassarino MF, Genua M, et al. Insulin analogues differently activate insulin receptor isoforms and post-receptor signalling. Diabetologia 2010;53(8):1743-53.

153. Vigneri R, Goldfine ID, Frittitta L. Insulin, insulin receptors, and cancer. Journal of endocrinological investigation 2016;39(12):1365-76.

154. Qi C, Bin L, Yang Y, et al, Glipizide suppresses prostate cancer progression in the TRAMP model by inhibiting angiogenesis. Sci Rep 2016;6:27819.

155. Gier B, Krippeit-Drews P, Sheiko T, et al. Suppression of KATP channel activity protects murine pancreatic beta cells against oxidative stress. J Clin Invest 2009;119(11):3246-56.

156. Sliwinska A, Rogalska A, Szwed M, et al. Gliclazide may have an antiapoptotic effect related to its antioxidant properties in human normal and cancer cells. Mol Biol Rep 2012;39(5):5253-67.

157. Sliwinska A, Sliwinski T, Kasznicki J, et al. Effect of gliclazide on nucleotide excision repair (NER) and non-homologous DNA end joining (NHEJ) in normal and cancer cells. J Physiol Pharmacol 2010;61(3):347-53.

158. Pasello G, Urso L, Conte $P$, et al. Effects of sulfonylureas on tumor growth: a review of the literature. Oncologist 2013;18(10):1118-25.

159. Sawada F, Inoguchi T, Tsubouchi H, et al. Differential effect of sulfonylureas on production of reactive oxygen species and apoptosis in cultured pancreatic beta-cell line, MIN6. Metabolism 2008;57(8):1038-45.

160. Nunez M, Medina V, Cricco G, et al. Glibenclamide inhibits cell growth by inducing G0/G1 arrest in the human breast cancer cell line MDA-MB-231. BMC Pharmacol Toxicol 2013;14:6.

161. Ardehali H, O'Rourke B. Mitochondrial K(ATP) channels in cell survival and death. J Mol Cell Cardiol 2005;39(1):7-16. 
162. de Sant'Anna JR, Franco CC, Mathias PC, et al. Assessment of in vivo and in vitro genotoxicity of glibenclamide in eukaryotic cells. PLoS One 2015;10(3):e0120675.

163. El Sharkawi FZ, El Shemy HA, Khaled HM. Possible anticancer activity of rosuvastatine, doxazosin, repaglinide and oxcarbazepin. Asian Pacific journal of cancer prevention : APJCP 2014;15(1):199203.

164. Atsumi S, Nosaka C, Ochi Y, et al. Inhibition of experimental metastasis by an alpha-glucosidase inhibitor, 1,6-epi-cyclophellitol. Cancer Res 1993;53(20):4896-9.

165. Weaver GA, Tangel CT, Krause JA, et al. Biomarkers of human colonic cell growth are influenced differently by a history of colonic neoplasia and the consumption of acarbose. J Nutr 2000;130(11):2718-25.

166. Sun G, Kashyap SR. Cancer risk in type 2 diabetes mellitus: metabolic links and therapeutic considerations. J Nutr Metab 2011;2011:708183.

167. Quesada CF, Kimata H, Mori M, et al. Piroxicam and acarbose as chemopreventive agents for spontaneous intestinal adenomas in APC gene 1309 knockout mice. Jpn J Cancer Res 1998;89(4):392-6.

168. EMA. Actos: European public assessment report - Product Information. . Available at http://wwwemaeuropaeu/ema/indexjsp?curl=pages/medicines/human/medicines/000285/human med 000624jsp\&murl=menus/medicines/medicinesjsp\&mid=WC0b01ac058001d124 (last accessed 15 Aug 2015) 2012.

169. Dominick MA, White MR, Sanderson TP, et al. Urothelial carcinogenesis in the urinary bladder of male rats treated with muraglitazar, a PPAR alpha/gamma agonist: Evidence for urolithiasis as the inciting event in the mode of action. Toxicol Pathol 2006;34(7):903-20.

170. Long GG, Reynolds VL, Dochterman LW, et al. Neoplastic and non-neoplastic changes in F-344 rats treated with Naveglitazar, a gamma-dominant PPAR alpha/gamma agonist. Toxicol Pathol 2009;37(6):741-53.

171. Long GG, Reynolds VL, Lopez-Martinez A, et al. Urothelial carcinogenesis in the urinary bladder of rats treated with naveglitazar, a gamma-dominant PPAR alpha/gamma agonist: lack of evidence for urolithiasis as an inciting event. Toxicol Pathol 2008;36(2):218-31.

172. Suzuki S, Arnold LL, Pennington KL, et al. Effects of pioglitazone, a peroxisome proliferator-activated receptor gamma agonist, on the urine and urothelium of the rat. Toxicol Sci 2010;113(2):349-57.

173. Cohen SM. Urinary bladder carcinogenesis. Toxicol Pathol 1998;26(1):121-7.

174. Sato K, Awasaki $Y$, Kandori $H$, et al. Suppressive effects of acid-forming diet against the tumorigenic potential of pioglitazone hydrochloride in the urinary bladder of male rats. Toxicol Appl Pharmacol 2011;251(3):234-44.

175. Cohen SM. Effects of PPARgamma and combined agonists on the urinary tract of rats and other species. Toxicol Sci 2005;87(2):322-7.

176. Lubet RA, Fischer SM, Steele VE, et al. Rosiglitazone, a PPAR gamma agonist: potent promoter of hydroxybutyl(butyl)nitrosamine-induced urinary bladder cancers. Int J Cancer 2008;123(10):2254-9.

177. Oleksiewicz MB, Southgate J, Iversen L, et al. Rat Urinary Bladder Carcinogenesis by Dual-Acting PPARalpha + gamma Agonists. PPAR Res 2008;2008:103167.

178. Egerod FL, Svendsen JE, Hinley J, et al. PPAR alpha and PPAR gamma coactivation rapidly induces Egr-1 in the nuclei of the dorsal and ventral urinary bladder and kidney pelvis urothelium of rats. Toxicol Pathol 2009;37(7):947-58.

179. Egerod FL, Brunner N, Svendsen JE, et al. PPARalpha and PPARgamma are co-expressed, functional and show positive interactions in the rat urinary bladder urothelium. J Appl Toxicol 2010;30(2):151-62.

180. Chopra B, Hinley J, Oleksiewicz MB, et al. Trans-species comparison of PPAR and RXR expression by rat and human urothelial tissues. Toxicol Pathol 2008;36(3):485-95.

181. Hillaire-Buys D, Faillie JL, Montastruc JL, et al. Stay vigilant: a glitazone (pioglitazone) can hide a glitazar! Eur J Clin Pharmacol 2012;68(12):1681-3.

182. Orasanu G, Ziouzenkova O, Devchand PR, et al. The peroxisome proliferator-activated receptor-gamma agonist pioglitazone represses inflammation in a peroxisome proliferator-activated receptor-alphadependent manner in vitro and in vivo in mice. J Am Coll Cardiol 2008;52(10):869-81. 
183. Frohlich E, Wahl R. Chemotherapy and chemoprevention by thiazolidinediones. Biomed Res Int 2015;2015:845340.

184. Joshi H, Pal T, Ramaa CS. A new dawn for the use of thiazolidinediones in cancer therapy. Expert Opin Investig Drugs 2014;23(4):501-10.

185. Grommes C, Karlo JC, Caprariello A, et al. The PPARgamma agonist pioglitazone crosses the bloodbrain barrier and reduces tumor growth in a human xenograft model. Cancer Chemother Pharmacol 2013;71(4):929-36.

186. Bojkova B, Orendas $P$, Kubatka $P$, et al. Positive and negative effects of glitazones in carcinogenesis: experimental models vs. clinical practice. Pathol Res Pract 2014;210(8):465-72.

187. Burton JD, Goldenberg DM, Blumenthal RD. Potential of peroxisome proliferator-activated receptor gamma antagonist compounds as therapeutic agents for a wide range of cancer types. PPAR Res 2008;2008:494161.

188. Bjerre Knudsen L, Madsen LW, Andersen S, et al. Glucagon-like Peptide-1 receptor agonists activate rodent thyroid C-cells causing calcitonin release and C-cell proliferation. Endocrinology 2010;151(4):1473-86.

189. Byrd RA, Sorden SD, Ryan T, et al. Chronic Toxicity and Carcinogenicity Studies of the Long-Acting GLP1 Receptor Agonist Dulaglutide in Rodents. Endocrinology 2015;156(7):2417-28.

190. Rosol TJ. On-target effects of GLP-1 receptor agonists on thyroid C-cells in rats and mice. Toxicol Pathol 2013;41(2):303-9.

191. Hegedus L, Moses AC, Zdravkovic M, et al. GLP-1 and calcitonin concentration in humans: lack of evidence of calcitonin release from sequential screening in over 5000 subjects with type 2 diabetes or nondiabetic obese subjects treated with the human GLP-1 analog, liraglutide. J Clin Endocrinol Metab 2011;96(3):853-60.

192. Buteau J, Foisy S, Joly E, et al. Glucagon-like peptide 1 induces pancreatic beta-cell proliferation via transactivation of the epidermal growth factor receptor. Diabetes 2003;52(1):124-32.

193. Drucker DJ. Glucagon-like peptide-1 and the islet beta-cell: augmentation of cell proliferation and inhibition of apoptosis. Endocrinology 2003;144(12):5145-8.

194. Masur K, Schwartz F, Entschladen F, et al. DPPIV inhibitors extend GLP-2 mediated tumour promoting effects on intestinal cancer cells. Regul Pept 2006;137(3):147-55.

195. Kajiyama H, Kikkawa F, Suzuki T, et al. Prolonged survival and decreased invasive activity attributable to dipeptidyl peptidase IV overexpression in ovarian carcinoma. Cancer Res 2002;62(10):2753-7.

196. Liu MY, Zhang H, Hu YJ, et al. Identification of key genes associated with cervical cancer by comprehensive analysis of transcriptome microarray and methylation microarray. Oncol Lett 2016;12(1):473-78.

197. Beckenkamp A, Willig JB, Santana DB, et al. Differential Expression and Enzymatic Activity of DPPIV/CD26 Affects Migration Ability of Cervical Carcinoma Cells. PLoS One 2015;10(7):e0134305.

198. Khin EE, Kikkawa F, Ino K, et al. Dipeptidyl peptidase IV expression in endometrial endometrioid adenocarcinoma and its inverse correlation with tumor grade. Am J Obstet Gynecol 2003;188(3):670-6.

199. Mizokami Y, Kajiyama H, Shibata K, et al. Stromal cell-derived factor-1alpha-induced cell proliferation and its possible regulation by CD26/dipeptidyl peptidase IV in endometrial adenocarcinoma. Int J Cancer 2004;110(5):652-9.

200. Wesley UV, McGroarty M, Homoyouni A. Dipeptidyl peptidase inhibits malignant phenotype of prostate cancer cells by blocking basic fibroblast growth factor signaling pathway. Cancer Res 2005;65(4):1325-34.

201. Sun YX, Pedersen EA, Shiozawa Y, et al. CD26/dipeptidyl peptidase IV regulates prostate cancer metastasis by degrading SDF-1/CXCL12. Clin Exp Metastasis 2008;25(7):765-76.

202. Wang $\mathrm{H}$, Liu $X$, Long $M$, et al. NRF2 activation by antioxidant antidiabetic agents accelerates tumor metastasis. Sci Transl Med 2016;8(334):334ra51.

203. Zhao H, Wang L, Wei R, et al. Activation of glucagon-like peptide-1 receptor inhibits tumourigenicity and metastasis of human pancreatic cancer cells via PI3K/Akt pathway. Diabetes Obes Metab 2014;16(9):850-60. 
204. Amritha CA, Kumaravelu P, Chellathai DD. Evaluation of Anti Cancer Effects of DPP-4 Inhibitors in Colon Cancer- An Invitro Study. J Clin Diagn Res 2015;9(12):Fc14-6.

205. Choi HJ, Kim JY, Lim SC, et al. Dipeptidyl peptidase 4 promotes epithelial cell transformation and breast tumourigenesis via induction of PIN1 gene expression. Br J Pharmacol 2015;172(21):5096-109.

206. Jang JH, Baerts L, Waumans Y, et al. Suppression of lung metastases by the CD26/DPP4 inhibitor Vildagliptin in mice. Clin Exp Metastasis 2015;32(7):677-87.

207. Femia AP, Raimondi L, Maglieri G, et al. Long-term treatment with Sitagliptin, a dipeptidyl peptidase-4 inhibitor, reduces colon carcinogenesis and reactive oxygen species in 1,2-dimethylhydrazineinduced rats. Int J Cancer 2013;133(10):2498-503.

208. Luciani P, Deledda C, Benvenuti S, et al. Exendin-4 induces cell adhesion and differentiation and counteracts the invasive potential of human neuroblastoma cells. PLoS One 2013;8(8):e71716.

209. Nomiyama T, Kawanami T, Irie S, et al. Exendin-4, a GLP-1 receptor agonist, attenuates prostate cancer growth. Diabetes 2014;63(11):3891-905.

210. Tsutsumi $Y$, Nomiyama T, Kawanami T, et al. Combined Treatment with Exendin-4 and Metformin Attenuates Prostate Cancer Growth. PLoS One 2015;10(10):e0139709.

211. Scafoglio C, Hirayama BA, Kepe V, et al. Functional expression of sodium-glucose transporters in cancer. Proc Natl Acad Sci U S A 2015;112(30):E4111-9.

212. Villani LA, Smith BK, Marcinko K, et al. The diabetes medication Canagliflozin reduces cancer cell proliferation by inhibiting mitochondrial complex-I supported respiration. Mol Metab 2016;5(10):1048-56.

213. Novikov A, Vallon V. Sodium glucose cotransporter 2 inhibition in the diabetic kidney: an update. Curr Opin Nephrol Hypertens 2016;25(1):50-8. 